NASA Technical Memorandum 83730

AIAA-84-2205

\title{
Velocity and Temperature Characteristics of Two-Stream, Coplanar Jet Exhaust Plumes
}

U. von Glahn, J. Goodykoontz, and $\mathrm{C}$. Wasserbauer

Lewis Research Center

Cleveland, Ohio

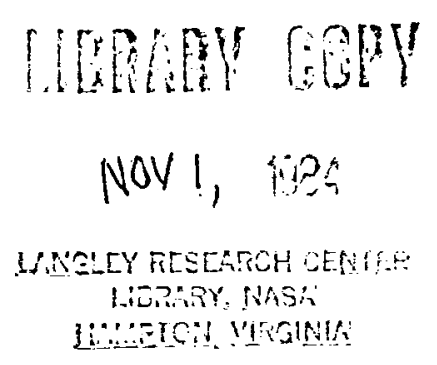

Prepared for the

Second Applied Aerodynamics Conference sponsored by the American Institue of Aeronautics and Astronautics Seattle, Washington, August 21-23, 1984 


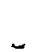

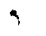


12 $1 \quad 1$ WhHCh- -839 DISH

940\% E-205 IAS WOTHE

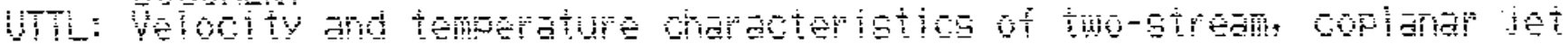
chingt ames

ATH: AOMLAL U.

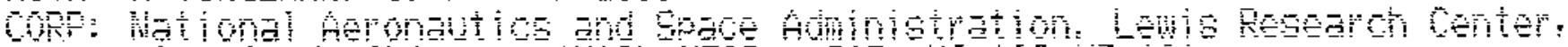

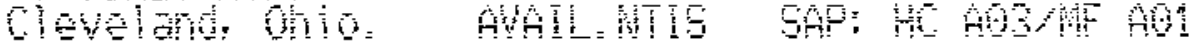

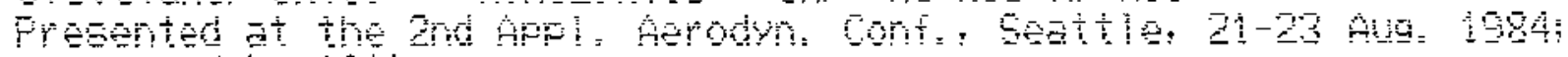
जopisole by

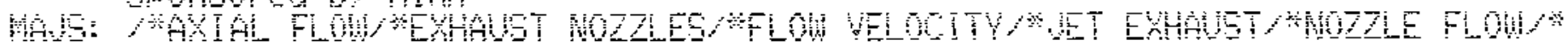
RADA FOM

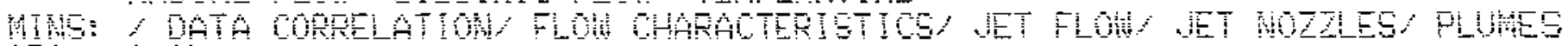

AOA A Hit

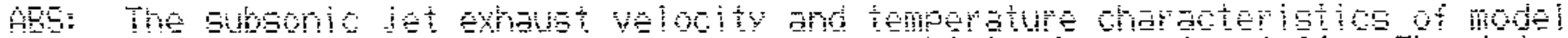

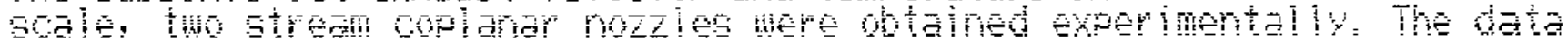

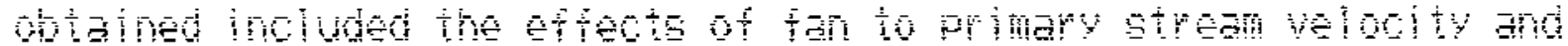

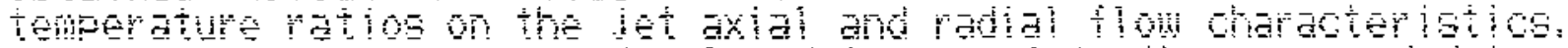

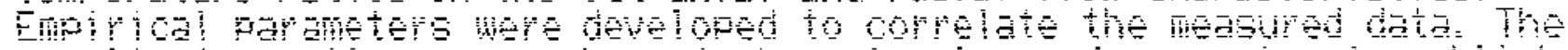

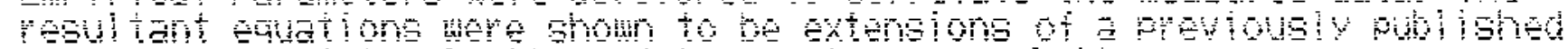

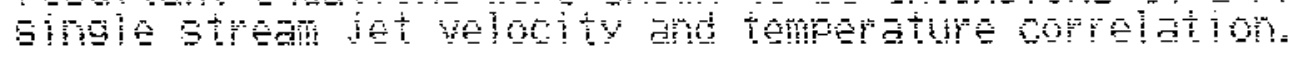

ENIEP 


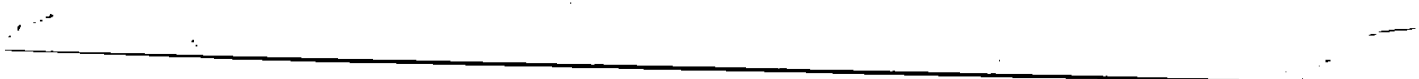


AIAA-84-2205

Velocity and Temperature Characteristics

of Two-Stream, Coplanar Jet

Exhaust Plumes

U. von Glahn, J. Goodykoontz,

and C. Wasserbauer, NASA Lewis Research

Center, Cleveland, $\mathrm{OH}$

\section{AIAA 2nd Applied Aerodynamics Conference}

August 21-23, 1984/Seattle, Washington 


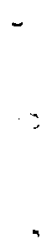


VELOCITY AND TEMPERATURE CHARACTERISTICS OF TWO-STREAM, COPLANAR JET EXHAUST PLUMES

U. von Glahn, J. Goodykoontz and C. Wasserbauer

National Aeronautics and Space Administration Lewis Research Center

Cleveland, Ohio 44135

\section{Abstract}

The subsonic jet exhaust velocity and temperature characteristics of model-scale two-stream coplanar nozzles were obtained experimentally. The data obtained includes the effects of fan-toprimary stream velocity and temperature ratios on the jet axial and radial flow characteristics. Empirical parameters were developed to correlate the measured data. The resultant equations are shown to be extensions of a previously published single-stream jet velocity and temperature correlation.

\section{Nomenclature}

$\begin{array}{ll}\begin{array}{ll}A, B, B_{1}, B_{2}, \\ F, F_{0}, F_{T}\end{array} & \text { normalizing factors } \\ A R & \text { nozzle fan-to-primary stream area ratio } \\ b_{V} & \text { radial location where } U_{R} / U_{C}=0.5 \\ b_{T} & \text { radial location where } t_{R} / t_{C}=0.5 \\ D & \text { diameter } \\ D_{T} & \text { total nozzle diameter } \\ h & \text { nozzle annulus height } \\ M & \text { Mach number } \\ R & \text { radial distance } \\ R_{J} & \text { primary nozzle exit radius } \\ T & \text { total temperature } \\ t & \text { static temperature } \\ U & \text { velocity } \\ X & \text { axial distance downstream of nozzle } \\ & \text { exit plane }\end{array}$

\section{Subscripts:}

$\begin{array}{ll}C & \text { local centerline peak level } \\ F & \text { fan } \\ J & \text { jet } \\ 0 & \text { ambient } \\ P & \text { primary } \\ R & \text { radial } \\ T & \text { temperature } \\ V & \text { velocity }\end{array}$

\section{Introduction}

In the operation of future aircraft, the control and modification of airflow over and about the vehicle will merit increasing consideration. A prime example is a short takeoff and landing aircraft (STOL), such as the proposed MCDonnell Douglas $\mathrm{C}-17$, that employs an under-the-wing blown flap for lift augmentation during takeoff and landing. For such an aircraft, the jet velocity and temperature impinging on the flap surfaces must be controlled in order to maintain flap loads and surface temperatures within acceptable limits for reasons of structural integrity and high-lift performance. Usually these requirements necessitate some means of enhanced jet mixing with the surrounding medium in order to reduce the loads and temperatures at the flap location.

In Ref. 1 , the mean-flow velocity and temperature characteristics associated with conical nozzle plumes were presented for both conventional and excited flow states. It was shown that jet plume mixing with the surrounding medium could be enhanced by acoustic excitation or aero/mechanical perturbation devices. Further information concerned with this phenomena, including flight effects are discussed in Refs. 2 and 3 , as well as several others in the literature.

In the present paper, subsonic jet plume velocity and temperature characteristics of conventional two-stream coplanar jet flows are presented. The data were obtained at model scale and cover several nozzle areas, flow rates and temperature levels. Evaluation of the data included consideration of both the axial and radial jet plume characteristics. Analyses herein include both existing relationships available in the literature as well as new or modified empirical correlations developed where such relationships are not presently available. A prime consideration for the latter was that the new correlating equations $c$ an be reduced to the correlations for single flow given in Ref. 1 .

The data and correlations included herein are intended to serve as a baseline for future twostream jet studies involved with jet plume modifications achievable using acoustic or aero/ mechanical means of flow excitation. Emphasis is placed on the centerline axial velocity and temperature decay characteristics of two-stream jet flows, with secondary considerations given to radial characteristics. The choice on the emphasis was dictated to some degree by the available data.

\section{Background}

Centerline Velocity Decay

In Ref. 1, the single-stream, unexcited jet centerline velocity decay for conical nozzles was correlated by the following relationship, slightly rewritten for the present work: 


$$
\frac{U}{U_{J}}=\left[1+\left(\left.\frac{x}{60 J \sqrt{1+M_{J}}}\left(\frac{t_{J}}{t_{0}}\right)^{0.25}\right|^{8}\right]^{-0.125}\right.
$$

Note that the static temperature ratio is used in Eq. (1). If the total temperature ratio is used in Eq. (1), the exponent for the temperature ratio is reduced from 0.25 to 0.215 in order for the correlated decay data to fall on substantialiy the same curve as that given by $\mathrm{Eq}$. (1).

In the present work, the single-stream nozzle data from Refs. 1 and 2 are used as baseline or reference values for the two-stream nozzle data. In Fig. 1, these baseline data are shown as a function of the parameters in Eq. (1), and it is apparent that Eq. (1) represents the data well.

\section{Centerline Temperature Decay}

The single-stream, unexcited jet centerline temperature decay for conical nozzles was correlated by the following relationship in Ref. 1, again slightly rewritten for the present work:

$\frac{t-t_{0}}{t_{J}-t_{0}}=\left[1+\left\{\frac{x}{50 J \sqrt{1+M_{J}}}\left(\frac{t_{J}}{t_{0}}\right)^{0.25}\right\}^{8}\right]^{-0.125}$

The preceding equation again is valid for static values rather than total values of the jet temperature. However, use of an exponent of 0.215 instead of 0.25 for the jet-to-ambient temperature ratio, as in the case of the centerline velocity decay, will coincide the total temperature decay curve with that for the static temperature decay curve.

The single-stream data are again used as the baseline or reference values for the two-stream nozzle data included in the present work. In Fig. 2, these baseline data are shown as a function of the parameters in Eq. (2). It is apparent that Eq. (2) represents the data well.

\section{Radial Velocity/Temperature Profiles}

Radial velocity and temperature profiles for single-stream jets are frequently represented by the following relationships:

$$
\frac{U_{R}}{U_{C}}=\left[1-\left(\frac{R}{2.27 b_{V}}\right)^{1.5}\right]^{2.0}
$$

taken from Ref. 4 and

$\frac{t_{R}-t_{0}}{t_{C}-t_{0}}$ or $\frac{T_{R}-t_{0}}{T_{C}-t_{0}}=\left[1-\left(\frac{R}{2.27 b(t \text { or } T)}\right)^{1.5}\right]^{2.0}$

Equation (4) is similar to that for the radial velocity profile (eq. (3)) differing only in that $b(t$ or $T)$ is used in place of $b_{v}$.

A comparison of typical data from Ref. 1 and the present work with Eqs. (3) and (4) is shown in
Fig. 3 for single-stream nozzles. It is apparent that Eqs. (3) and (4) represent the data in an acceptable manner.

\section{Apparatus and Procedure}

Facility

A photograph of the dual-stream heated-jet facility is shown in Fig. 4. Unheated laboratory air was used to supply flow for two parallel flow lines; one line for the inner nozzle and the other for the outer nozzle. Each flow line had its own air and fuel flow control and measuring systems. The air was heated by a jet engine combustor installed in each line. The system was designed to give maximum nozzle exhaust temperatures of about $1100 \mathrm{~K}$ and nozzle pressure ratios up to 3.0 in each of the flow lines.

\section{Nozzles}

Two different coaxial-coplanar nozzle configurations were used in the experimental program. Dimensions of the nozzles are given in Fig. 5 . The area ratios given in the figure are the ratios of the outer nozzle flow area to the inner nozzle flow area. The diameters are inside diameters of the respective nozzles. The inner nozzle was common to both configurations and the coaxial nozzle area ratio was changed by changing the outer nozzle. The outer wall of the inner nozzle was coated with a high temperature ceramic material to minimize heat transfer between the two streams. The interior of the upstream portion of the inner nozzle supply was also lined with insulating material.

\section{Instrumentation}

Flow system. Instrumentation was provided to measure air and fuel flow rates and nozzle total pressures and temperatures for both streams. Nozzle pressures and temperatures were measured at four different circumferential locations at approximately ten inner nozzle diameters upstream of the nozzle exit plane. In addition, six thermocouples were mounted to the wall of the outer nozzle so that radiation losses 5 for the interior thermocouples could be closely approximated.

Jet plume. Jet exhaust plume total pressure and temperature surveys were made with a probe capable of traversing in the axial, horizontal, and vertical directions, as illustrated in Fig. 6(a). Details of the probe are shown in Fig. 6(b). The probe was calibrated in a wind tunnel over a range of Mach numbers.

Procedure

Nozzle pressures and temperatures for both streams were varied over a range of conditions so that the test matrix included a wide range of velocity and temperature ratios.

Steady-state conditions were attained for each flow condition before pressures and temperatures were recorded. Upstream total temperatures were averaged and corrected for radiation losses and used with the average upstream pressure to calculate an ideal nozzle exhaust velocity. Static temperatures were derived from the total temperature and Mach number. All velocities were subsonic (nozzle pressure ratio less than 1.89); conse- 
quently, static pressures at the nozzle exit and downstream in the jet plume were assumed to be atmospheric.

Measurements in the jet plume included probe position, total temperature and total pressure. Probe radial traverses were made along the horizontal centerline of the nozzle, in a step-wise fashion, at various axial locations. Total temperature was corrected for radiation losses and derodynamic recovery errors. 5 The recovery factors for cold flow were determined from the probe calibration tests and extrapolated to higher temperatures by the method suggested in Ref. 6 . Local velocities were then calculated from the total pressure and corrected total temperature.

\section{General Plume Characteristics}

\section{Plume Centerline Characteristics}

In this section the two-stream plume centerline velocity and temperature characteristics are discussed in terms of general trends with stream velocity and temperature ratios. In the latter case, the trends are essentially similar for both static and total stream temperatures.

Velocity. In Fig. 7, the trend of the jet centerline velocity decay, U/Up, at a given primary stream Mach number is shown schematically as a function of the axial distance downstream of the nozzle exit plane. The two velocity decay curves shown in the figure represent the case with primary flow only and that with equal velocity in the fan and primary streams. In the latter case because the nozzle is coplanar, the reference nozzle diameter is the diameter of the outer nozzle. With cold flow in both streams, the velocity decay curve shifts generally to the right with increasing $\mathrm{U}_{F} / \mathrm{Up}_{\mathrm{p}}$ values. However, as indicated by the reversal in the $U_{F} / U_{p}$ arrow, an abrupt change in the decay characteristics was observed and will be discussed later in more detail. With hot primary flow and cold fan flow, the decay curve at a given $U_{F} / U_{p}$ ratio tended to shift somewhat to the right (i.e.; greater $X / D p$ values relative to the curve with both streams cold).

The velocity decay curves shown schematically in Fig. 7 are typical of those obtained in static experiments, i.e., no flight effects. It can be argued that near the nozzle exit plane, the fan stream surrounding the primary stream provides a local flight effect and, consequently, the decay curve is more complex than the simple representation shown in Fig. 7. The more complex situation is shown schematically in $F$ ig. 8 . In region $A$, Fig. 8, velocity decay is a function of $\left(U-U_{F}\right) /$ $\left(U_{p}-U_{F}\right)$ instead of $U / U_{p}$, as for static conditions. Here the fan velocity, $U_{F}$, represents a local or pseudo flight velocity. When the primary and fan flows are fully mixed (region C) the jet centerline velocity decay is again a function of $U / U_{p}$, as for a single stream under static conditions. However, relative to region $A$, the curve in region $C$ is displaced due to a transition region (region $B$ in Fig. 8 ). The location and extent of region $B$ would depend on the nozzle exhaust velocity and temperature ratios. In general, for the range of data obtained with the area ratio 1.9 and 3.2 nozzles, this pseudo flight effect was not observed or could be neglected. However, with the nozzle having an area ratio of 25,2 there was some evidence of such a flight effect because the $U / U_{p}$ and $\left(U-U_{F}\right) /\left(U_{p}-U_{F}\right)$ data plots tended to coincide. In no case did the $U / U_{p}$ versus $X / D_{p}$ plots indicate the $U / U_{p}$ data becoming asymptotic to the $U_{F} / U_{P}$ ratio, a further proof that the possible "flight" effect of the fan stream on the primary stream was not significant over the wide range of conditions included in the present work.

Temperature. The effect of the fan-to-primary stream velocity ratio on the jet centerline temperature decay was significantly different from that observed for velocity decay. The trend of the temperature decay curve with velocity ratio is shown schematically in Fig. 9. Initially, at $U_{F} / U_{P}$ values of 0.3 , the temperature decay curve with heated primary and cold fan flows shifted to the right from the zero fan flow curve denoted by $U_{F} / U_{p}=0$. At $U_{F} / U_{p}$ of 0.3 , the decay curve shifted to the left, even beyond the Dp curve for a single-stream nozzle. Furthermore, the slope of the decay curve steepened with increasing values of $U_{F} / U_{p}$, as will be shown later. The data also showed a jog in the trend similar to that observed in the velocity decay data and occurring in about the same region of $U_{F} / U_{P}$ values. With increasing fan stream temperatures and a constant primary stream temperature, the decay curves shifted to the right as indicated in Fig. 9 In all cases, independent of the velocity ratio, when the two-stream temperatures were the same, the two-stream decay curves coincided with the DT curve; this again will be shown later in detail.

\section{Plume Radial Characteristics}

The plume radial velocity and temperature profiles for two-stream nozzles showed the presence of the separate fan and primary streams in the region from the nozzle exit plane to about the end of the primary core region. Thereafter, the two streams had merged sufficiently to exhibit essentially a single radial profile more typical of a single-stream plume.

In the analyses of these profiles in the core region ( $f$ ig. 10), it was necessary to extend the local velocity and temperature decay curves in order to estimate $R / R_{0.5}$ values for $t / t_{0.5}$ and $U / U_{0.5}$. At $U_{F} / U_{P}$ values less than 0.5 this extension was not needed for the primary stream edge decay because the fan stream departed from primary stream edge decay curve below the one-half velocity or temperature ratio point. The radial velocity and temperature edge decay for the fan stream, prior to merging with the primary stream, was also analyzed and compared with the radial decay of single nozzles.

\section{Typical Data}

\section{Centerline Velocity Decay}

Representative jet plume centerline velocity decay data are shown in Fig. 11, and include: (1) both streams cold for several fan-to-primary stream velocity ratios, and (2) hot primary stream with cold fan flow and also various amounts of fan stream heating for nominal fan-to-primary velocity ratios of 0.30 and 0.68 . 
The data in Fig. 11 are for an area ratio, AR, of 1.9; however, similar trends were obtained with an area ratio, AR, of 3.2. While the data shown are plotted as a function of primary stream static temperature in the abscissa, similar results were obtained using the total temperature.

In Fig. 11(a) the effect of increasing the fan-to-primary stream velocity ratio (both streams cold) is to shift the decay curve increasingly to the right of the single-stream curve, $U_{F} / U_{P}=$ 0 . With a fan-to-primary velocity ratio of 1.0 , the curve designated $U_{F} / U_{P}=1.0$ is reached.

In Figs. 11(b) and (c), the effect of absolute stream temperatures and ratios on the plume centerline velocity decay is shown for nominal UF/UP ratios of 0.30 and 0.68 , respectively. The effect of increasing the primary flow static temperature from cold $(236 \mathrm{~K})$ to a nominal static temperature of $1035 \mathrm{~K}$ with a cold fan flow is almost negligible and taken into consideration sufficiently by the parameters in the abscissa. However, with a heated fan stream, the data tend to shift to the right, toward the $U_{F} / U_{p}=1.0$ curve. The shift increases with increasing temperature level.

\section{Centerline Temperature Decay}

Examples of jet plume centerline temperature decay are shown in Figs. 12 to 14 . The data shown are again for an AR of 1.9 and include: (1) heated primary stream with cold fan flow, and (2) both streams heated.

In Fig. 12, both static and total temperature decay data are for the case of a heated primary stream and cold fan flow. It is apparent that there is little difference in the decay rates for total and static temperatures except at very high UF/Up ratios. However, as indicated previously the temperature decay curves at low $U_{E} / U_{P}$ ratios shift to the right of the single flow curve; whereas at high $U_{F} / U_{p}$ ratios, the curves shift to the left of the single flow curve. Note also that the slope of the temperature decay curves becomes steeper with increasing UF/Up ratios. This latter trend is shown more clearly in Fig. 13 where curves drawn through the data in Fig. 12 are normalized to a $\left(t-t_{0}\right) /\left(t_{p}-t_{0}\right)$ ratio of 0.5 at an abscissa value of 10 . Also shown, for comparison, is the single-stream temperature decay curve from Ref. 1. Although the curves shown in Fig. 13 are for static temperatures, it is obvious from Fig. 12 that similar trends occur for total temperatures.

In Fig. 14(a) and (b) are shown the effects of heating the fan stream on the temperature decay for a heated primary stream for nominal fan-toprimary velocity ratios of 0.30 and 0.68 . The data are for the static temperature decay; however, similar trends were obtained for the total temperature decay.

The data shown in Fig. 14 indicate that the temperature decay curves relative to the cold fan flow data shift to the right with increasing fanto-primary stream temperature ratios. It is interesting to note that when the fan-to-primary stream temperature ratio is near 1.0 , the data coincide with the $D_{T}$ curve, independent of the $U_{F} / U_{P}$ ratio. This is shown clearly in $\mathrm{Fig}$. 14 (c) for several $U_{F} / U_{P}$ ratios.
Radial Velocity Profiles

In Figs. 15 and 16 are shown typical radial velocity profiles at several axial distances from the nozzle exit plane. The data shown include: (1) both streams with cold flow, (2) heated primary stream with a cold fan stream, and (3) both streams heated.

In Fig. 15, radial velocity profiles are shown for a nominal fan-to primary velocity ratio of 0.30 and with only the primary stream heated. The data indicate that separate identification of the $f$ an stream in the profile exists to an $x / D p$ of less than four. With a higher fan-to-primary velocity ratio of about 0.68 , shown in $\mathrm{Fig}$. 16 , the identification of the $f$ an stream in the radial velocity profile depends somewhat on the fan stream temperature, varying from an $X / D p$ of less than four for cold flows to about eight for hot flows. of particular interest is Fig. 16(b) in which the $f$ an stream is cold but the primary stream is hot. A comparison of these data with those in Figs. $16(a)$ and (c) shows that the primary stream is considerably smaller in radial extent even at an $X / 0 p$ of 1.0 , than for the cases in which both streams are either cold or hot; however, the total radial extent of the streams in the core region is substantially the same in all three cases.

Data obtained with the 3.2 area ratio nozzle were similar to those for the 1.9 area ratio noz$z l e$; however, due to the larger fan nozzle, the fan stream radial velocity profiles were wider and persisted to greater downstream distances, even at low UF/Up ratios.

Radial Temperature Profiles

Representative radial temperature profiles at several axial distances downstream of the nozzle exit plane are shown in Figs. 17 and 18. The data include: (1) heated primary with a cold fan stream, and (2) both streams heated.

In Fig. 17 are shown the radial temperature profiles associated with the radial velocity profiles shown previously in Fig. 15 for a nominal fan-to-primary velocity ratio of 0.30 . Because the fan stream is unheated, no evidence of the fan stream is discernible in the temperature profiles.

In Figs. 18(a) and (b) are shown the radial temperature profiles associated with the radial velocity profiles shown previously in Figs. 16(b) and $(c)$, respectively. It is apparent in Fig. 18(a) that the cold fan stream causes a rapid cooling of the primary stream as evidenced by the rapid reduction of the radial profile. When the two streams are well mixed downstream, the radial temperature profile is much broader than that near the nozzle exit; however, the temperatures of the mixed flow are greatly reduced as shown by the centerline temperatures listed in the figure. From these data and that shown in Fig. $16(\mathrm{~b})$, it is apparent that a cold fan stream, due to its mixing/cooling effects on the primary stream causes a very marked reduction in the primary stream temperature characteristics.

When both streams are heated, the primary stream radial temperature extent is increased, as shown by the profiles in Fig. 18(b) compared with 
those in Fig. 18(a). Also the presence of the heated fan stream is evident in the radial profile to $X / D p$ ratios between four and eight for the stream conditions noted in the figure.

As for the radial velocity profiles, the fan stream radial temperature profiles for the 3.2 area ratio nozzle were wider than those for the 1.9 area ratio nozzle and persisted as a separate identity for a longer axial distance. The trends with velocity and temperature ratio were similar for both nozzles.

It should be noted that although the radial temperature profiles shown in Figs. 17 and 18 are in terms of static temperatures, the total temperature profiles were substantialiy similar except at the radial profile extremities.

\section{Plume Centerline Decay Correlations}

All correlation efforts herein had as their ultimate objective the reduction of the two-stream plume data to that given by the single-stream curves given in Ref. 1. To that end, any additional parameters used to correlate the two-stream data either had to reduce to 0 or 1.0 when $U_{F} / U_{p}$ was 0 or 1.0, depending on the particular equation formulation.

\section{Velocity}

In order to reduce the two-stream centerline velocity decay data to the single-stream curve given by Eq. (1), the data were adjusted by a factor denoted by $F_{V}$. This factor was determined to be a function of mainly $U_{F} / U_{P}$ and secondarily of the total-to-primary nozzle diameter ratio, and the primary and fan stream temperatures. The correlation parameter, $F_{V}$ is expressed as:

$$
\frac{F_{V}-1}{\left(D_{T / D_{P}}-1\right)} \propto\left(\frac{U_{F}}{U_{P}}\right)^{A}
$$

where:

$$
A=\left[0.625\left(\frac{D_{T}}{D_{P}}\right)\left(\frac{t_{0}}{t_{P}}\right)^{0.2}\left(\frac{t_{0}}{t_{F}}\right)^{0.5}\right]
$$

In the exponent $A$, a nozzle size term was required because the slope of the curve through a given set of nozzle data appeared to be a function of $D_{T} / D_{p}$. Similarly, changes in the stream temperatures also affected the slope of the data. Consequently, an exponential formulation to account for these effects was used and so that when $U_{F} / U_{p}=0$, the FV parameter was 1.0; hence, the single-stream formulation. Similarly, with a primary stream diameter of $D_{P}$ when $U_{F} / U_{P}=1.0$, the $F_{V}$ parameter was $D_{T} / D_{p}$, or the single stream formulation with a stream diameter consisting of the total diameter, DT. Use of total stream temperatures in Eq. (5) would cause the exponents on the respective temperature ratios to be 0.1785 and 0.39 .

The correlation parameter, FV, in terms of these relationships is shown in Fig. 19. This figure includes data for the AR 1.9 and 3.2 nozzles from the present work and the AR 25 nozzle from Ref. 2. Note that the data from Ref. 2 was a free-jet simulated flight effects study using a single nozzle. However, the free jet can also be considered as a very large fan stream nozzle.

From the correlation shown in Fig. 19, it is evident that at least two main flow regimes are present with a transition region between them. An equation was developed to include all three regions. The equation selected consists of two parts; first, a linear relation for the entire range of data and second, a subtractive term that operates primarily in the $\left(U_{F} / U_{P}\right)^{A}$ range of 0.7 to 1.0 and accounts for the dip or deviation of the data from the linear relationship. This equation is given by:

$$
\begin{gathered}
\frac{F_{V}-1}{\left(\frac{D_{T}}{D_{P}}-1\right)}=\left(\frac{U_{F}}{U_{P}}\right)^{A}-0.125\left[\left(\frac{U_{F}}{U_{P}}\right)^{8 A}\left\{1-\left(\frac{U_{F}}{U_{P}}\right)^{A}\right\}\right]^{4} \\
-0.275\left[\left(\frac{U_{F}}{U_{P}}\right)^{5 A}\left\{1+\left(\frac{U_{F}}{U_{P}}\right)^{A}\right\}\right]^{45}
\end{gathered}
$$

While the exponents in Eq. (7) appear to be horrendous, their use is caused by the steepness of the data trends in the $\left(U_{F} / U_{\rho}\right)^{A}$ range of 0.7 to 1.0 . The measured correlation parameter Fy values are shown in Fig. 20 together with the curve resulting from the use of $\mathrm{Eq}$. (7) for $\left(U_{F} / U_{p}\right)^{A}$ values greater than 0.4 . It is apparent that the agreement is good. For $\left(U_{F} / U_{p}\right)^{A}$ values less than 0.7 , the linear relationship shown by $\mathrm{Eq} .(7)$ in the figure is maintained.

For applications in which only a limited range of $\left(U_{F} / U_{P}\right)^{A}$ values are of interest, the main flow regimes can also be represented by the following equations. In the range of $\left(U_{F} / U_{P}\right)^{A}$ ratios less than 0.785 , the following relationship applies.

$$
\frac{\mathrm{F}_{V}-1}{\left(\mathrm{D}_{\mathrm{T} /} \mathrm{D}_{\mathrm{P}}-1\right)}=\left(\frac{\mathrm{U}_{\mathrm{F}}}{\mathrm{U}_{\mathrm{P}}}\right)^{\mathrm{A}}
$$

In the range of $\left(U_{F} / U_{P}\right)^{A}$ ratios greater than 0.815 , the following relationship represents the data well:

$$
\frac{F_{V}-1}{\left(D_{T /} D_{P}-T\right)}=\left[\left(\frac{U_{F}}{U_{P}}\right)^{A}\right]^{3.33}
$$

Finally, in the transition region $0.785<\left(U_{F} / U_{P}\right)^{A}$ $<0.815$, the following equation is valid:

$$
\frac{\mathrm{F}_{V}-1}{\left(\mathrm{D}_{\mathrm{T} /} \mathrm{D}_{\mathrm{P}}-1\right)}=\left[1.3\left(\frac{\mathrm{U}_{\mathrm{F}}}{\mathrm{U}_{\mathrm{P}}}\right)^{\mathrm{A}}\right]^{-12}
$$

Equations (8) to (10) are shown plotted in Fig. 21 together with the $F V$ values of Fig. 19. It is apparent that these equations also represent the data well, as was the case with Eq. (7).

In Fig. 22, the correlated two-stream centerline velocity decay data are shown in terms of $U / U_{p}$ as a function of 


$$
\frac{X}{D_{P} \sqrt{1+M_{p}}}\left(\frac{t_{p}}{t_{0}}\right)^{0.25}\left(\frac{1}{F_{V}}\right)
$$

where $F_{Y}$ is obtained from Eq. (7). Also shown is the single-stream curve from Ref. 1 . It is apparent that good correlation of the two-stream velocity decay data has been achieved and that the correlated data fall near the single-stream curve. Use of Eqs. (8) to (10) yield equaliy good correlation of the two-stream data within their respective ranges of application.

\section{Temperature}

It was stated earlier that the jet plume centerline temperature decay differed markedly in its trends compared with those for the centerline velocity decay. As was the case for the centerline velocity decay, the objective of the centerline temperature decay correlation for two-stream noz$z$ les was to provide the necessary parameters to reduce these data to the single-stream curve. of Ref. 1.

The first step in the present correlation was to adjust the slopes of the two-stream temperature decay curves (figs. 12 and 13) to that for the single-stream temperature decay curve. This adjustment was made by providing a suitable exponent to the static temperature ratio $\left(t-t_{\rho}\right) /\left(t_{p}-t_{\rho}\right)$ or the total temperature ratio $\left(T-t_{0} \rho\right) /\left(T_{p}-t_{0} \rho\right)$. For the static temperature ratio, the exponent, designated $B$, is given by:

$$
\begin{aligned}
& B=\left[1+\left(2.33\left(\frac{U_{F}}{U_{P}}\right)^{1.5}\right)\left(1-\sqrt{\frac{T_{F}-t_{0}}{T_{P}-t_{0}}}\right)\right]^{-1.00} \\
& \text { i.e., }\left[\frac{\left(t-t_{0}\right)}{\left(t_{P}-t_{0}\right)}\right]^{B} \text { or }\left[\frac{\left(T-t_{0}\right)}{\left(T_{P}-t_{0}\right)}\right]^{B}
\end{aligned}
$$

For $U_{F} / U_{P}$ ratios greater than about 0.9 , the addition of the term $0.67\left(U_{F} / U_{P}\right)^{8}$ to the $U_{F} / U_{P}$ portion of Eq. (11) provides a better correlation of the data without significantly affecting the correlation at lower values of the $U_{F} / U_{p}$. Inclusion of this additional term in Eq. (11) yields the following expanded equation:

$$
\begin{aligned}
& B_{1}=\left[1+\left\{2.33\left(\frac{U_{F}}{U_{P}}\right)^{1.5}+0.67\left(\frac{U_{F}}{U_{P}}\right)^{8}\right\}\right. \\
&\left.\left\{1-\sqrt{\frac{T_{F}-t_{0}}{T_{P}-t_{0}}}\right\}\right]^{-1.0}
\end{aligned}
$$

For the total temperature ratio, the exponent, designated $B_{2}$, is given by:

$\left.B_{2}=\left[1+\left\{1.667\left(\frac{U_{F}}{U_{P}}\right)^{1.5}\right\} \mid 1-\sqrt{\frac{T_{F}-t_{0}}{T_{P}-t_{0}}}\right)\right]^{-1.0}$
Representative center line temperature decay data in terms of $\left[\left(t-t_{0}\right) /\left(t_{p}-t_{0}\right)\right]^{B}$ as a function of

$$
\frac{x}{D_{p} \sqrt{1+M_{P}}}\left(\frac{t_{p}}{t_{0}}\right)^{0.25}
$$

are shown in Fig. 23. Also shown for comparison is the single-stream centerline temperature decay curve shape. It is apparent that the slopes of the two-stream data are the same as that for the single-stream curve. Plots of the centerline total temperature decay showed similar good agreement.

The next step in the correlation of the center1 ine temperature decay was to correlate the heated primary stream and cold fan stream data. A complex equation was required because of the reversal of the decay curves with $U_{F} / U_{P}$ ratio noted earlier in the discussion of Fig. 9. A suitable correlation parameter was developed that satisfied the end conditions where $U_{F} / U_{P}=0$ and 1.0 . This parameter, $F_{0}$, is given by:

$$
\begin{aligned}
F_{0}=1+\left(\frac{D_{T}}{D_{P}}-1\right) & {\left[\left\{4.4 \frac{U_{F}}{U_{P}}\left(1+\frac{U_{F}}{U_{P}}\right)^{2.5}\right\}\right.} \\
& \left.+\left\{\frac{98\left[1-\left(\frac{U_{F}}{U_{P}}\right)^{2}\right]}{e^{3 /\left(U_{F /} U_{P}\right)}}\right)^{4}\right]
\end{aligned}
$$

This parameter applies for both the static and total temperature decay curves for the data range included herein.

In order to correlate the temperature decay when both streams are heated, the parameter, $F_{0}$, was expanded as follows:

$$
F_{T}=F_{0}+\left(\frac{D_{T}}{D_{P}}-F_{0}\right)\left(\frac{T_{F}-t_{0}}{T_{P}-t_{0}}\right)^{0.5}
$$

The centerline temperature decay data are thus correlated by:

$$
\left(\frac{t-t_{0}}{t_{p}-t_{0}}\right)^{B}\left[\frac{x}{D_{P} \sqrt{1+M_{P}}}\left(\frac{t_{P}}{t_{0}}\right)^{0.25}\left(\frac{1}{F_{T}}\right)\right]
$$

or

$\frac{T-t_{0}}{T_{P}-t_{0}} \times\left[\frac{x}{D_{P} \sqrt{1+M_{P}}}\left(\frac{T_{P}}{t_{0}}\right)^{0.225}\left(\frac{1}{F_{T}}\right)\right]$

In Figs $24(a)$ and (b), the centerline static temperature decay is shown correlated in terms of $\mathrm{Eq}$. (16) for cold fan streams and heated $f$ an streams, respectively. Also shown for comparison is the single-stream decay curve from Ref. 1 . In general, the correlated two-stream data group well about the single-stream curve from Ref. 1 . 


\section{Radial Profiles}

Velocity

For single stream, turbulent flow jet plumes, the radial velocity distribution can be plotted in the non-dimensional parameters of $U_{R} / U_{C}$ as a function of R/by for specified axial locations downstream of the nozzle exit plane. ${ }^{4}$ Typical radial velocity distributions for the primary nozzle only (single stream) with heated flow are shown in Fig. 25.

In the present work, the $U_{R} / U_{C}$ distributions for two-stream flows were analyzed using the same parameters as for single-stream flows. In Fig. 26 are shown typical radial velocity distributions with both streams cold. Also shown in Fig. 26 for comparison is the single-stream radial velocity distribution curve from Ref. 4 . It is apparent that initially the two-stream radial velocity decay coincides with the single-stream curve until $U_{R} / U_{C}=U_{F} / U_{P}$, then the two-stream data departs from the single-stream curve with increasing R/bv, $P$ values. Near the nozzle exit $p l$ ane the departure and increase in $R / b y, P$ is a function of the nozzle size ratio $\left(D_{\mathrm{T}} / \mathrm{D}_{\mathrm{P}}\right)$, as well as the $U_{F} / U_{p}$ ratio. With increasing axial distance the deviation of the two-stream data from the single-stream curve is reduced until, when the fan and primary streams are well mixed, the two-stream data essentially coincides with the single-stream curve.

Similar data to that shown in Fig. 26 are shown in Fig. 27 for flows with only a heated primary stream and with both streams heated. The data trends noted for the cold flow data also apply to the heated flow data.

Examination of the radial velocity decay of the fan stream flow at $U_{R} / U_{C}=U_{F} / U_{P}$ in the initial decay region only indicates that this portion of the plume (see fig. 10) also follows the single-stream radial velocity distribution curve. An example of data from this part of the radial velocity profile is shown in Fig. 28 . The data used for this figure are based on the fan stream data shown previously in Fig. $27(d)$ over a range of nominal $x / D p$ values from 1 to 4 .

\section{Temperature}

The single-stream radial static temperature distribution plotted in terms $\left(t_{R}-t_{0}\right) /\left(t_{C}-t_{0}\right)$ as a function of $R / b_{T}$, is shown in $\mathrm{Fig}$. 29 for several axial distances downstream of nozzle exit plane. Also shown is a curve taken from Ref. 1 . The data are seen to be in good agreement with the curve. Similar good agreement is obtained when total temperatures are used.

In Fig. 30, representative radial temperature distributions for two-stream flows with only the primary stream heated are shown for nominal $U_{F} / U_{P}$ ratios of 0.29 and 0.68 . In general, the twostream data are closely representated by the single-stream curve except at $\left(t_{R}-t_{0}\right) /\left(t_{C}-t_{0}\right)$ ratios less than about 0.3 . In this latter region, higher temperature ratios are indicated by the data at the same R/bT,P for the two-stream flow than those with single-stream flow. The departure of the data from the single-stream curve appears to occur when the $\left(t_{R}-t_{0}\right) /\left(t_{C}-t_{0}\right)$ ratio equals the $t_{F} / t_{P}$ ratio.

In Fig. 31 , the radial temperature distribution for nozzle area ratios of 1.9 and 3.2 are shown for a nominal $U_{F} / U_{p}$ of 0.68 and both streams heated. The departure of the two-stream data from the single-stream curve is now quite evident. The departure appears to be initiated again when $\left(t_{R}-t_{0}\right) /\left(t_{C}-t_{0}\right)=t_{F} / t_{P}$, as in the case of the cold flow data.

The effect of heating the fan stream becomes very evident when $\left(t_{R}-t_{0}\right) /\left(t_{C}-t_{0}\right)=$ $\left(t_{F}-t_{0}\right) /\left(t_{p}-t_{0}\right)$, as noted in Fig. 31 . At the departure point, the radial temperature decay becomes nearly flat for a significant $R / b_{T}, P$ distance before again decaying as the outer region of the plume is approached. A comparison of the AR 1.9 with the AR 3.2 nozzle data shows that this constant temperature ratio region is widest with the larger area ratio nozzle, as would be expected.

As was done with the radial velocity profiles, the outer edge of the $f$ an stream region was also plotted in terms of $t_{R, F}-t_{0} / t_{C}, F-t_{0}$ as a function of $R / b_{T} F$. The results of this exercise are shown in Fig. 32 and indicate that the outer edge of the fan stream in the jet core region again follows the relationships established for single-stream radial velocity profiles.

In general, similar results are obtained if total temperatures are used in place of the static temperatures shown in the previous several figures. The primary differences between the use of total or static temperatures occur at very low temperature ratios at the outer plume edge that are generally of little interest for design or performance studies.

Plume Radial Spreading Rate

Velocity

The radial spreading of the jet plume velocity with axial distance is determined at the $U / U_{C}$ $=0.5$ radial location, by. In Fig. 33 , the single nozzle jet velocity spreading, bV, normalized to the nozzle exit plane radius, $R_{J}$, is shown as a function of the axial distance given by $X / R J$. Initially, in the core region, the radial spreading angle is about $6^{\circ}$, similar to that given in Ref. 2. However, downstream of the core region the angle was reduced to about $2^{\circ}$.

In order to obtain a correlation of the twostream primary flow spreading, the data were first evaluated for cold flow only. Reasonable correlation of the cold flow data was achieved by including a function of $D_{T} / D_{P}$ in both the abscissa and ordinate of Fig. 33. However, the heated twostream data required an additional term involving the UF/Up ratio. The final correlation parameters are shown in Fig. 34 together with the data and the single-stream curve. Reasonable correlation of the data were achieved by the parameters shown in the figure.

The radial spreading of the $f$ an stream in the core region is shown in Fig. 35. For the fan flow, the dimensional parameter is based on the width of the fan annulus, $h$, instead of $D p$ as in the 
case of the primary stream. Also shown in the figure is the single-stream curve, for which $h=R_{J}$. Because of the limited data available no further effort to normalize the data was attempted.

\section{Temperature}

In Fig. 36 , the temperature radial spreading with axial distance from the nozzle exit plane is shown for single-stream flows. These data were obtained at the same time as the velocity radial spreading data shown in Fig. 33 and are used herein as reference for the two-stream temperature radial spread data.

The temperature radial spreading for the twostream flow obtained in the present study was not sufficient to permit the development of correlation parameters; however, significant trends are shown in Fig. 37. The temperature radial spreading for the primary stream, bT $p / R p$, is shown as a function of the axial distance, $X / R_{p}$. Initially, the two-stream data coincide with the single stream curve. However, between $4<x / R p<8$, the twostream data deviates from the single-stream curve. Beyond $X / R p=8$, the two-stream data tends to parallel the single-stream curve. No explanation is currently available for the low values measured for the $A R=1.9$ nozzle at a $U_{F} / U_{P}=0.68$. It is speculated that with values of $U_{F} / U_{P}$ greater than 0.68 , the two-stream data approaches more closely to the single-stream curve; however, data are not available to provide the necessary normalization parameter.

In the case of the fan stream temperature radial spreading, even less data were available than that for the primary stream. The currently available data are shown in Fig. 38 in which bT,F/h is plotted as a function of $X / h$. Also shown in the figure is the single-stream curve. No further attempt was made to normalize the few data available.

\section{Concluding Remarks}

The present study has been restricted to coplanar two-stream nozzles having a circular primary nozzle. However, limited centerline velocity and temperature decay data were also obtained in the work of Ref. 7 with a non-coplanar nozzle with an area ratio of 1.2. The fan exit was nominally four primary nozzle diameters upstream of the primary nozzle exit. Analysis of the existing data indicated that the fan plume velocity and temperature decayed from the fan nozzle exit plane to the primary nozzle exit plane. Consequently, the primary stream decay would be a function of: an effective $U_{F} / U_{P}$ and $T_{F} / T_{P}$, and an effective total plume diameter. The limited available data were insufficient to determine the necessary correlation parameters for non-coplanar nozzles.

Many two-stream nozzles, aside from being noncoplanar also utilize a plug in the primary stream nozzle. The effect of such a plug on the jet plume velocity and temperature decay and spreading rate were not included in the present study and requires further experimental work.
Conclusions

0n the basis of the present study on subsonic two-stream jet plume characteristics the following conclusions may be drawn.

1. Centerline single-stream jet plume correlation parameters were extended to include twostream velocity and temperature effects. The resultant correlations are equally applicable to both single and dual-stream, coplanar jet plumes. Included in the correlated data bank are the effects of fan-to-primary stream velocity ratio and temperature ratio. Also included is the effect of fan-to-primary nozzle area ratio.

2. In general, the radial velocity and temperature profiles, particularly at high fan-to-primary velocity ratios, upstream of the primary core flow region must be analyzed independently to account for the individual flows. Downstream of the primary core flow region, the profiles are similar for the single and dual flows.

3. On the basis of limited data, a tentative correlation was developed for the two-stream radial velocity spreading rate. The resultant correlation is applicable to both single and dual flow jet plumes.

4. A correlation of two-stream temperature spreading rates was not possible due to the extremely limited data; however, sufficient data were available to discuss trends caused by fan-toprimary velocity and temperature ratios.

5. On the basis of a single set of plume velocity and temperature data, tentative recommendations for future work and possible data analysis considerations of non-coplanar nozzle flows are included.

\section{REFERENCES}

1. von Glahn, U. H., "On Some Flow Characteristics of Conventional and Excited Jets," AIAA Paper 84-0532, Jan. 1984.

2. Ahuja, K. K., Lepicovsky, J., Tam, C. K. W., Morris, P. J., and Burrin, R. H., "Tone Excited Jet," NASA CR 3538, 1982.

3. von Glahn, U. H., "Correlation of Flight Effects on Centerline Velocity Decay for ColdFlow Acoustically Excited Jets," NASA TM-83502, 1982.

4. Glass, D. R., "Effects of Acoustic Feedback on the Spread and Decay of Supersonic Jets," AIAA Journal, Vol. 6, No. 10, 1968 pp. 1890-i897.

5. Glawe, G.E., Simmons, F. S., and Stickney, T. M., "Radiation and Recovery Corrections and Time Constants of Several Chromel-Alumel Thermocoup le Probes in High-Temperature, HighVelocity Gas Streams," NACA TN $3766,1956$.

6. Glawe, G. E., Holanda, R., and Krause, L. N., "Recovery and Radiation Corrections and Time Constants of Several Sizes of Shielded and Unshielded Thermocouple Probes for Measuring Gas Temperature," NASA TP-1099, 1978. 
7. Stone, J. R., Goodykoontz, J. H., and Gutierrez, 0. A., "Effects of Geometry and Flow-Field Variables on Inverted-VelocityProfile Coaxial Jet Noise - Nozzle Geometry," NASA TM-79095, 1979. 


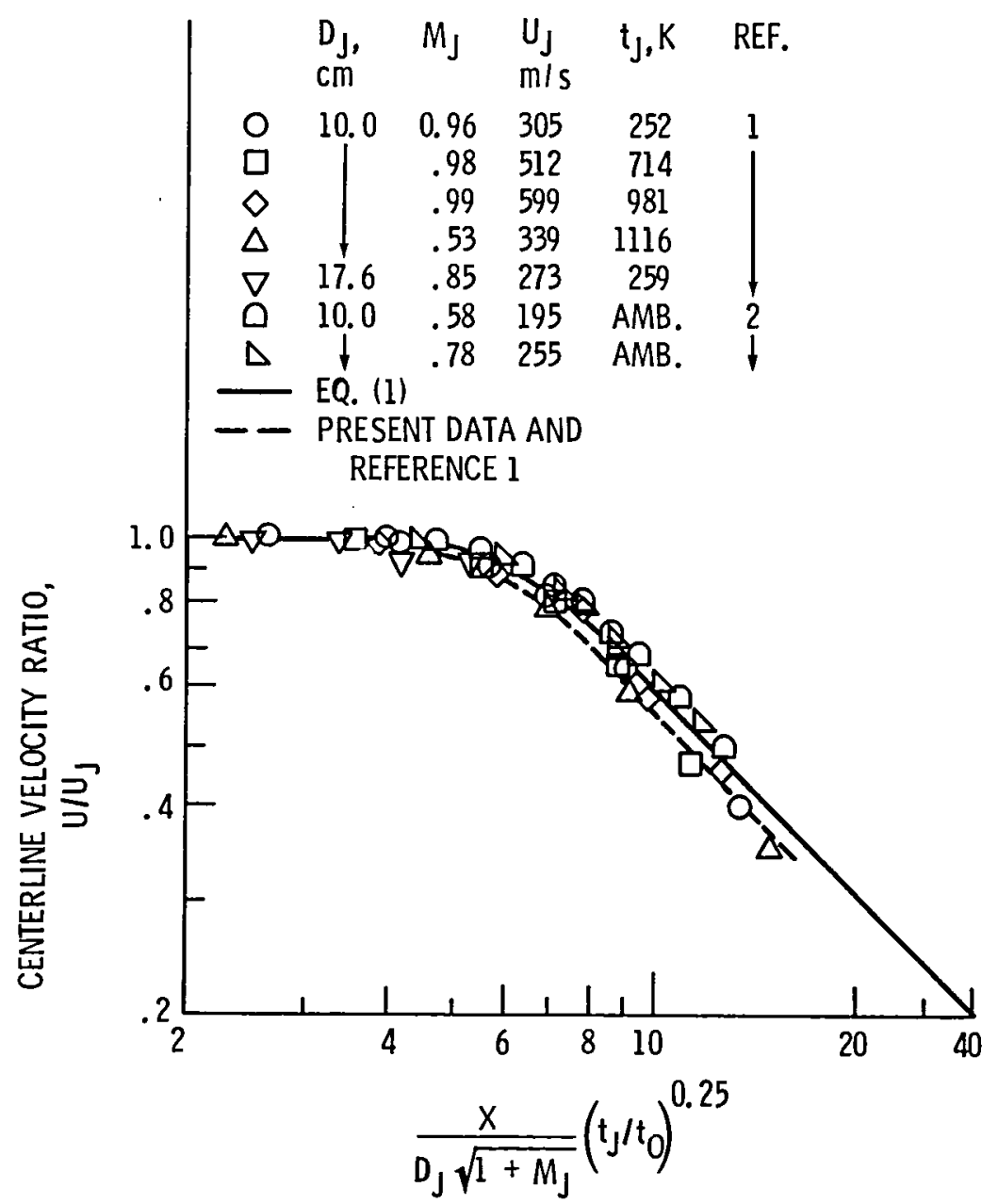

Figure 1. - Single-stream centerline velocity decay.

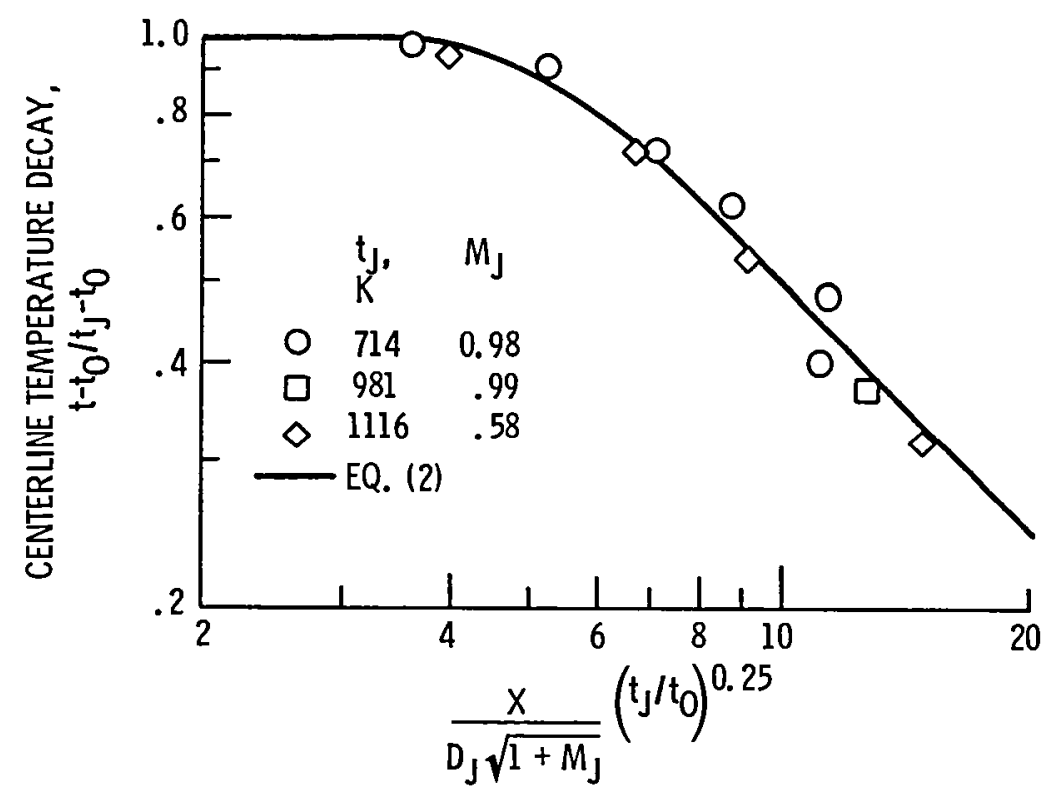

Figure 2. - Single-stream centerline static temperature decay. Ref. 1 ; D , $10 \mathrm{~cm}$. 

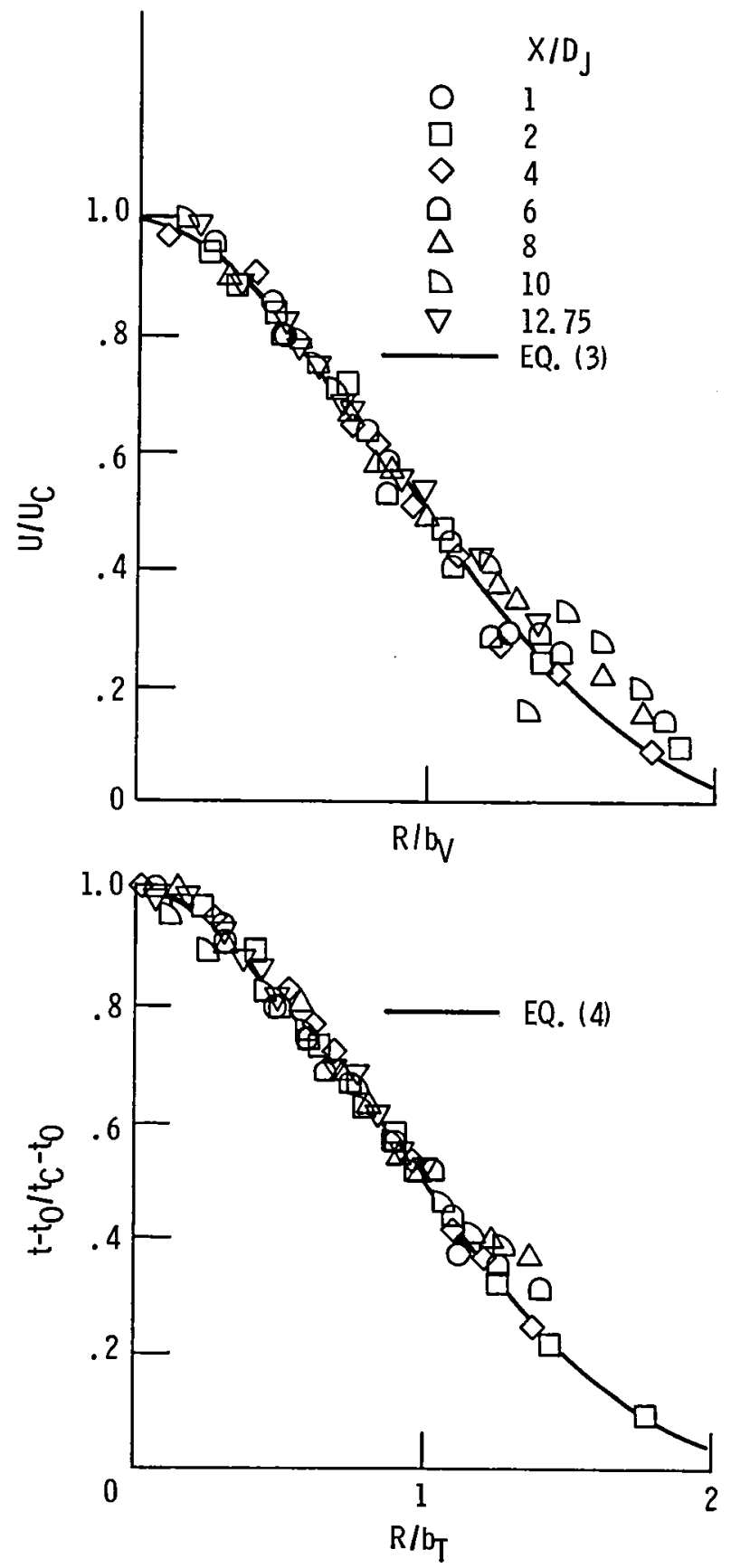

Figure 3. - Typical single-stream radial velocity and temperature profiles. Conical nozzle; $M J, .99 ; t_{\jmath}, 981 \mathrm{~K} ; D_{J}, 10 \mathrm{~cm}$; present data and ref. 1. 


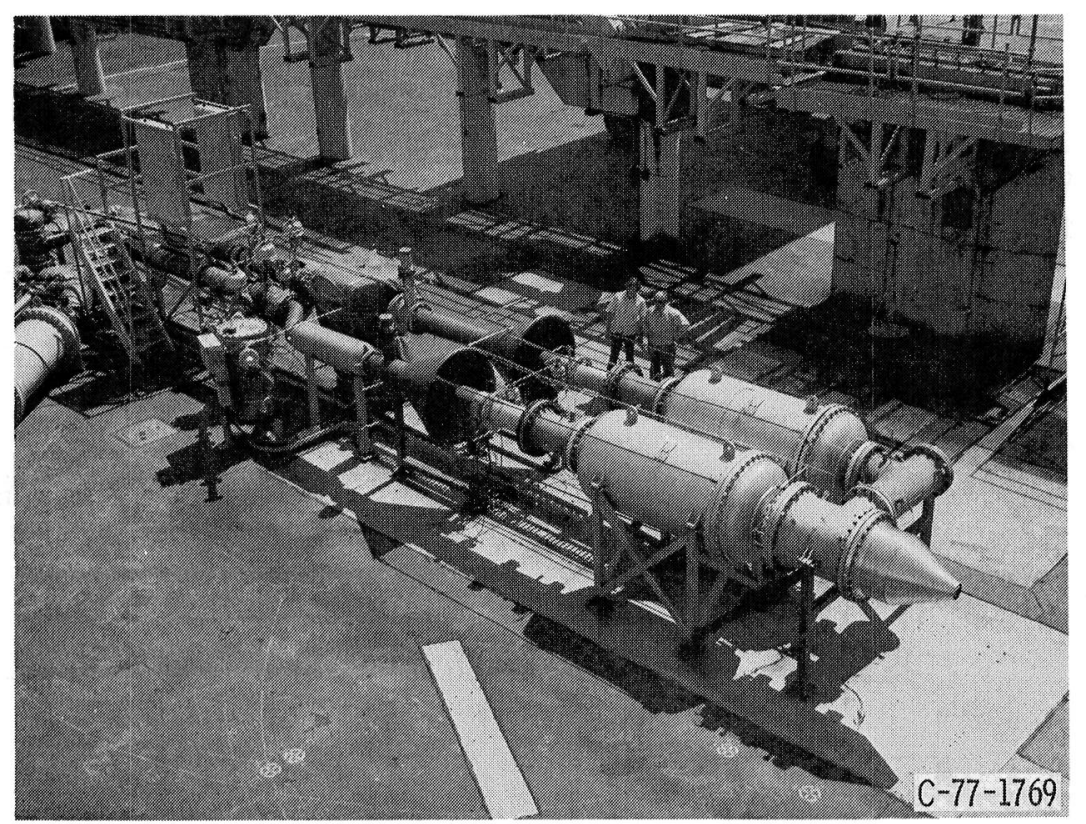

Figure 4. - Coaxial nozzle flow facility.

\begin{tabular}{|l|l|l|l|}
\hline $\begin{array}{c}\text { NOZZLE } \\
\text { AREA } \\
\text { RATI0 }\end{array}$ & $\begin{array}{l}\mathrm{D}_{\mathrm{T}} \\
\mathrm{cm}\end{array}$ & $\begin{array}{l}\mathrm{D}_{\mathrm{P}} \\
\mathrm{cm}\end{array}$ & $\begin{array}{l}\alpha, \\
\mathrm{deg}\end{array}$ \\
\hline 3.2 & 21.0 & 10.0 & 25.7 \\
\hline 1.9 & 17.6 & 10.0 & 27.0 \\
\hline
\end{tabular}

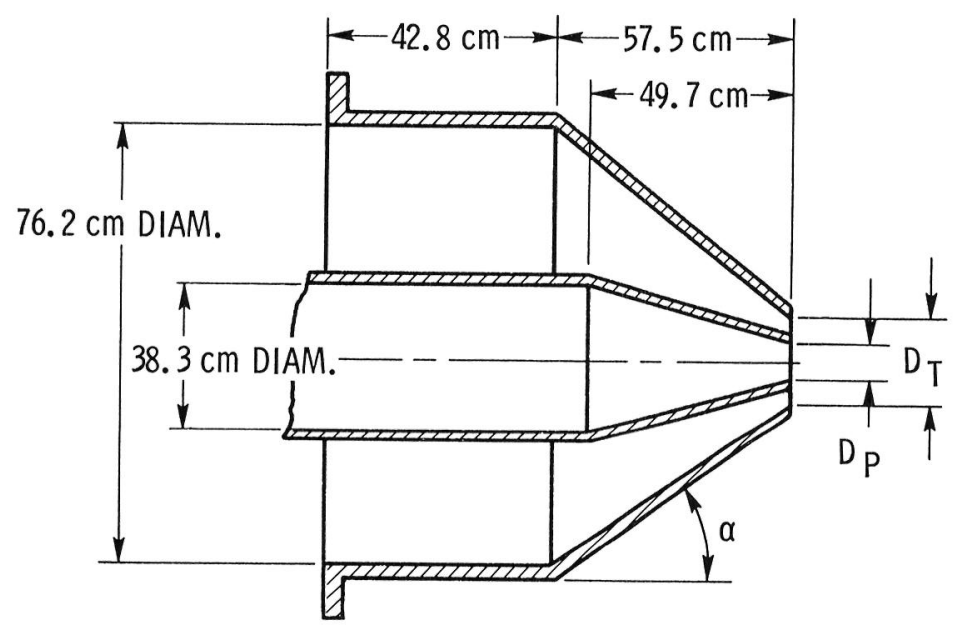

Figure 5. - Coplanar nozzle dimensions. 

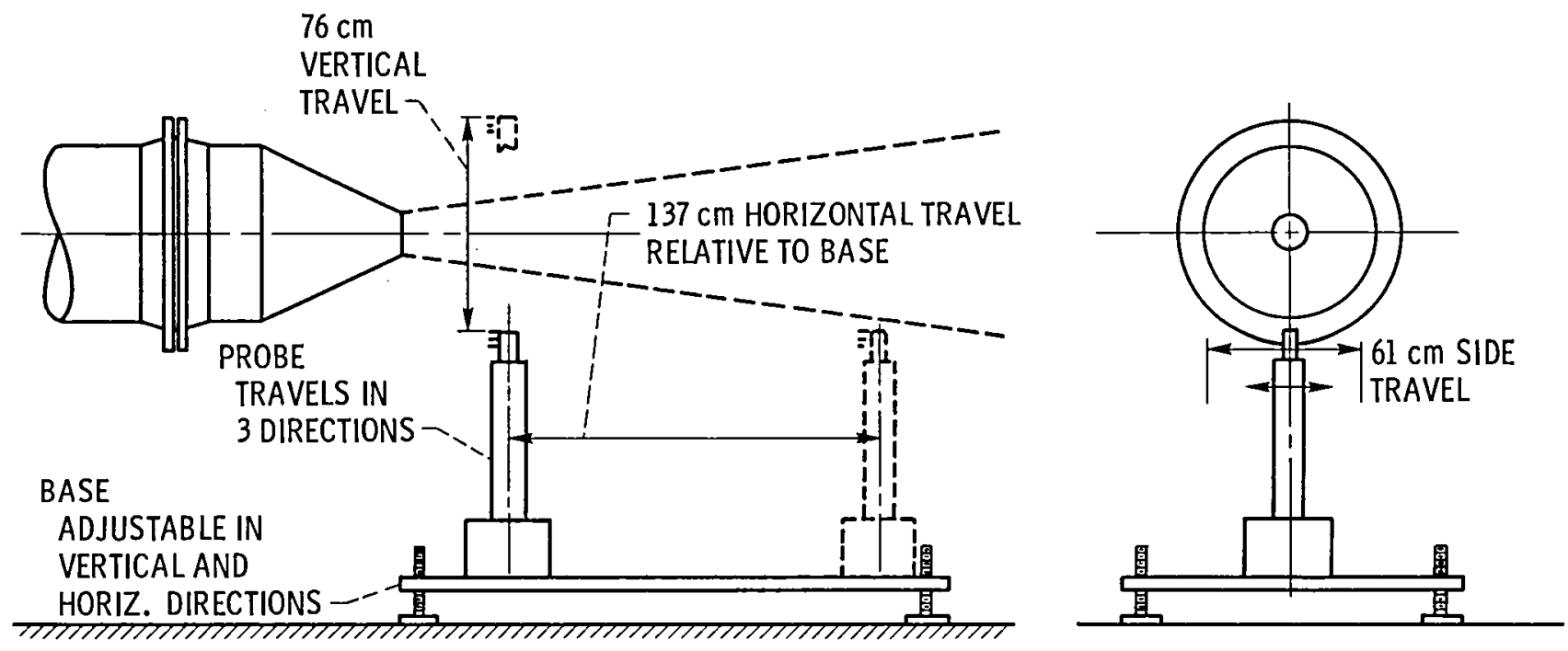

(a) Jet plume survey arrangement.

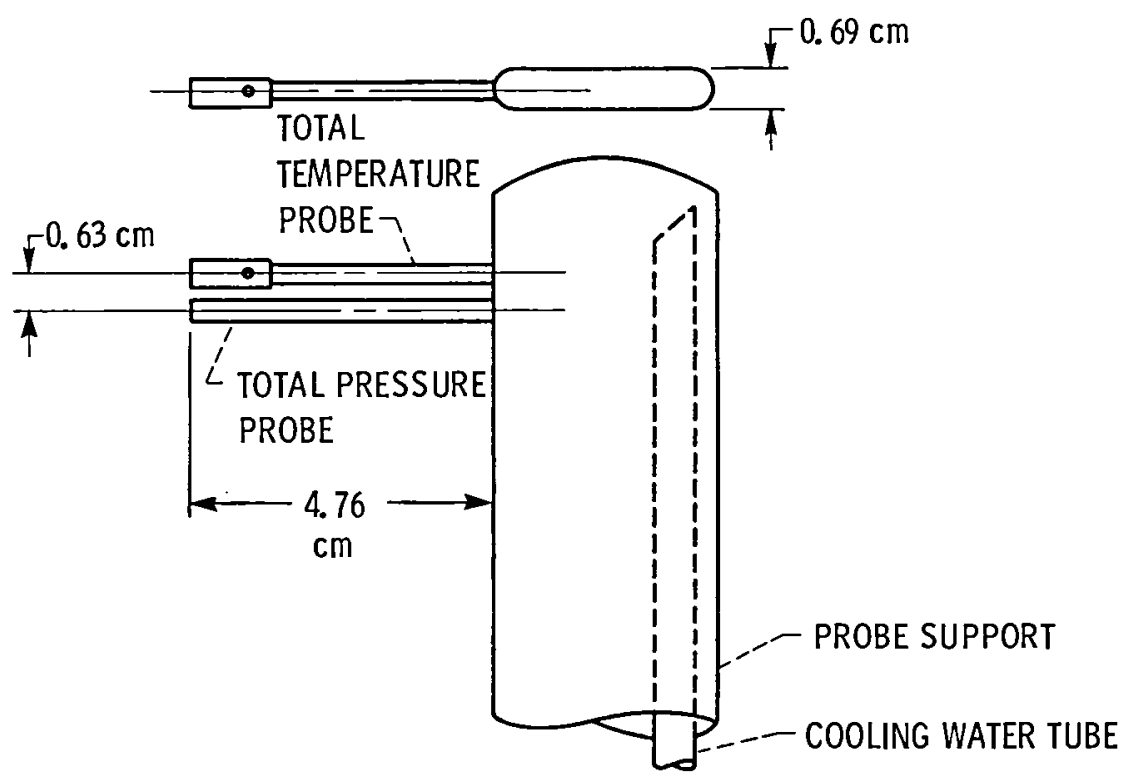

(b) Probe details.

Figure 6. - Jet plume survey apparatus. 


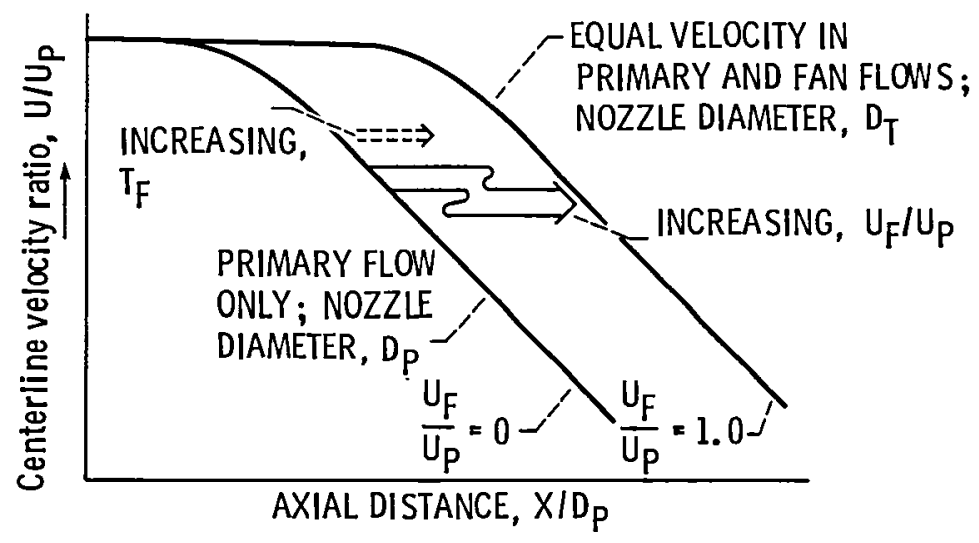

Figure 7. - Schematic showing effect of fan-to-primary velocity ratio and fan temperature on two-stream centerline velocity decay.
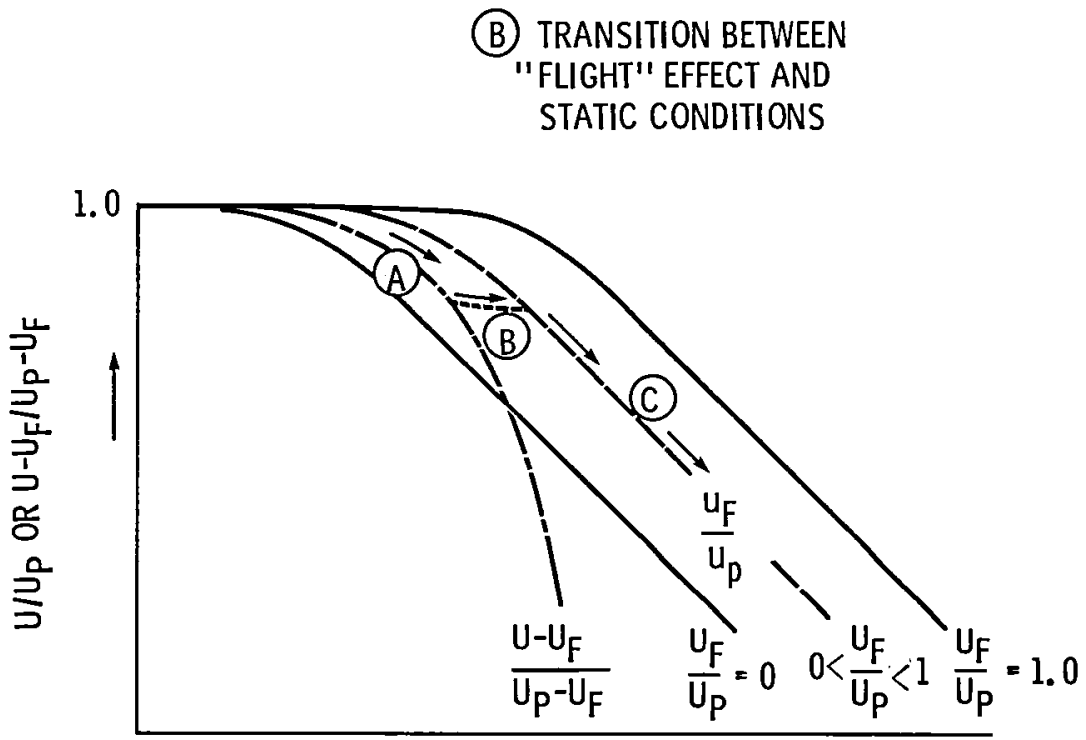

AXIAL DISTANCE, X/DP

Figure 8. - Schematic sketch of local "flight" effect of fan stream on two-stream centerline velocity decay. 


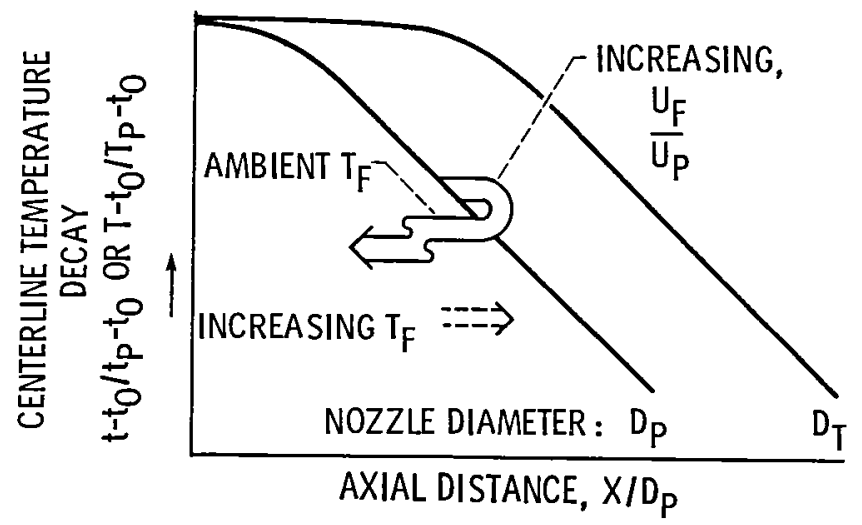

Figure 9. - Schematic showing effect of fan-toprimary stream velocity ratio and fan temperature on two-stream centerline temperature decay. 


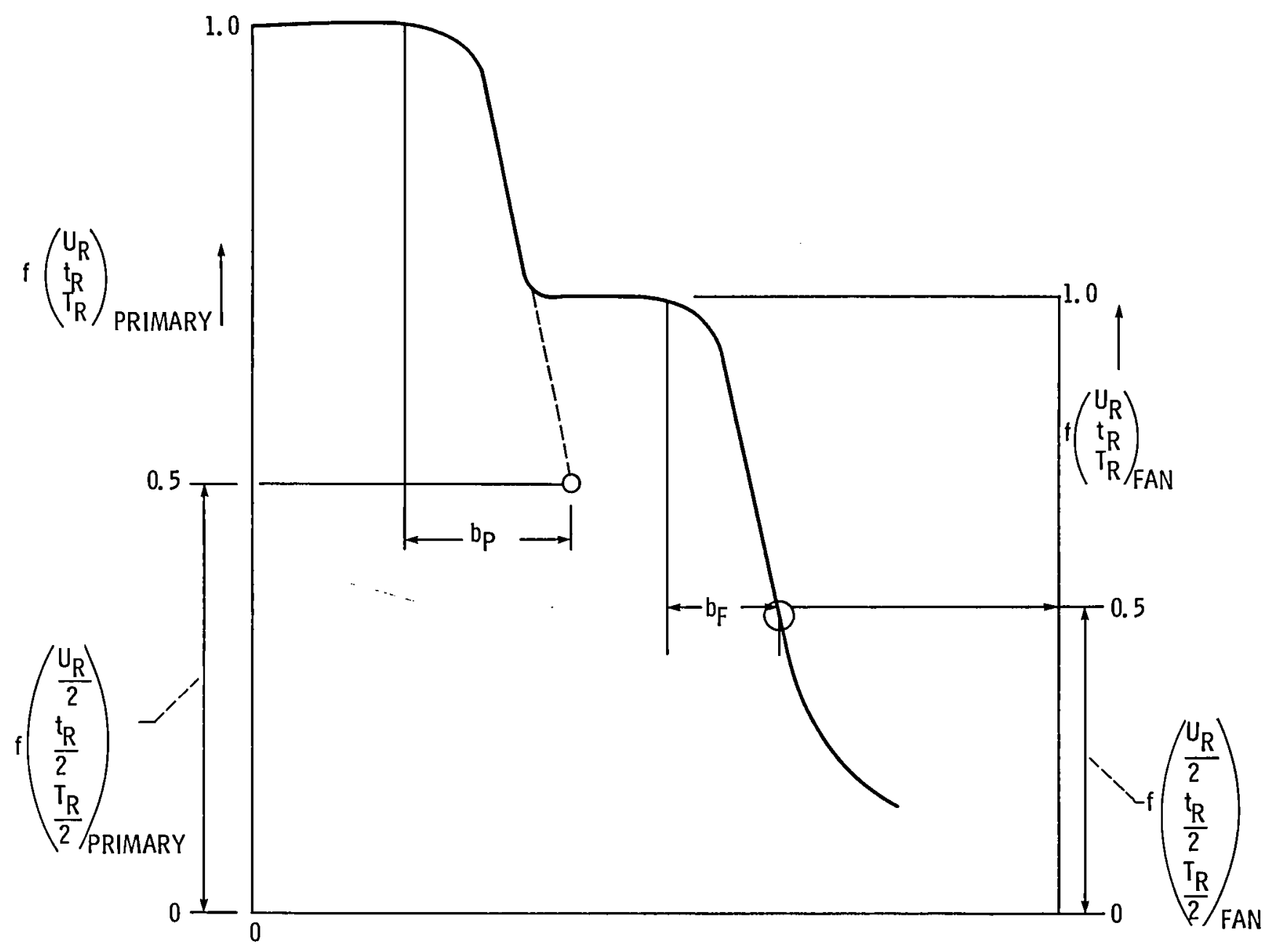

Figure 10. - Schematic sketch of radial velocity and temperature profile in core region showing pertinent variables. 


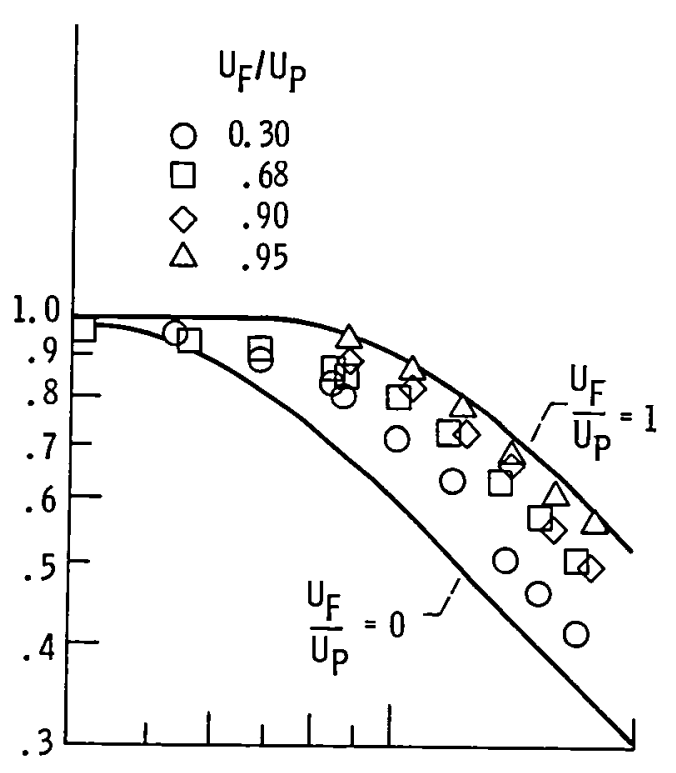

(a) Both streams cold.

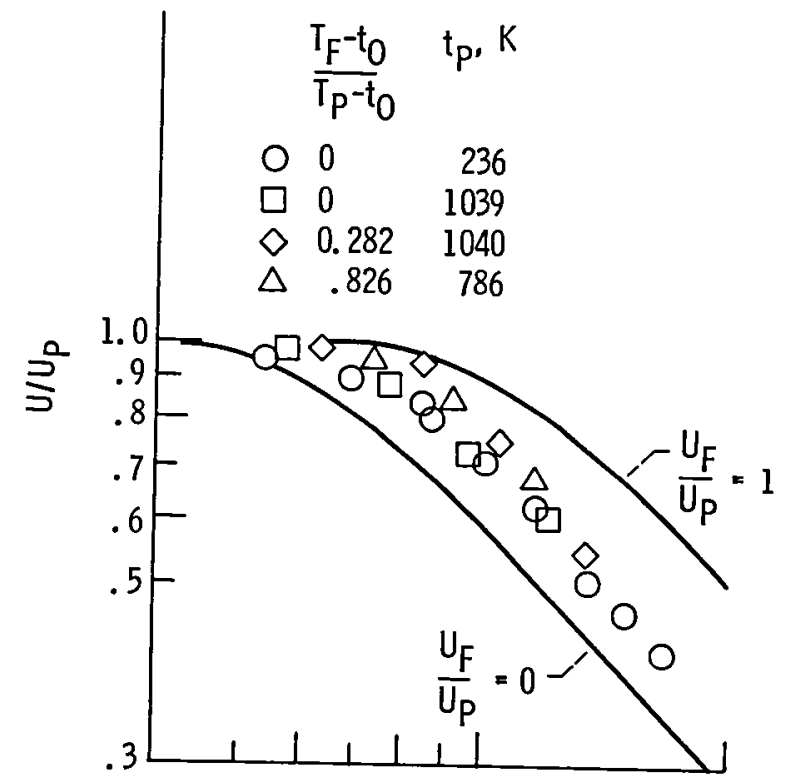

(b) $U_{F} / U_{P}=0.30$.

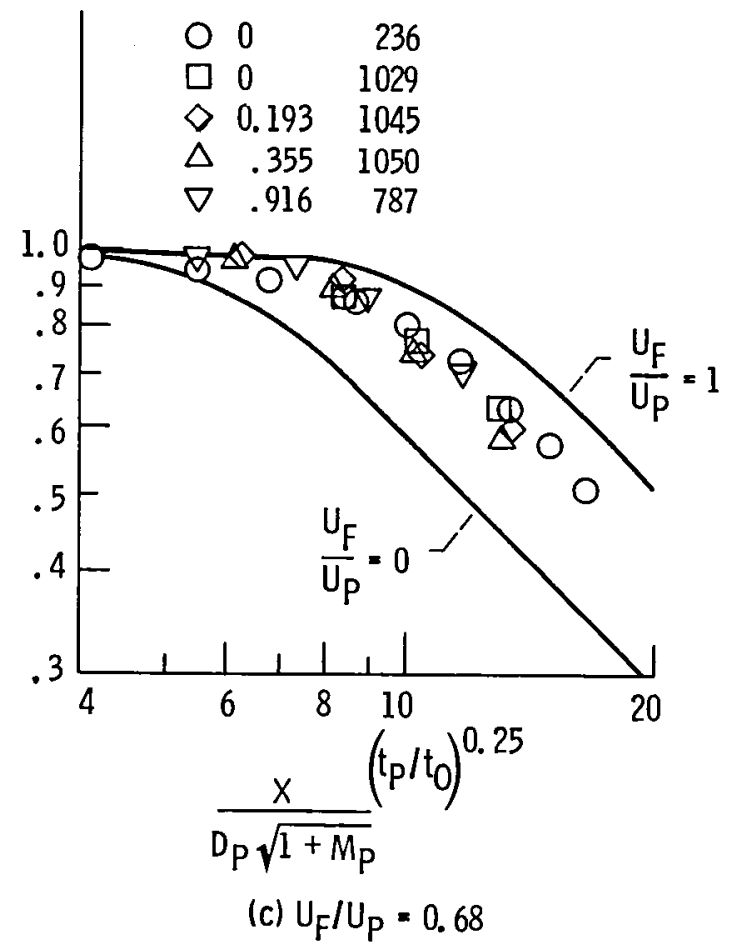

Figure 11. - Typical jet centerline velocity decay characteristics. Nozzle AR, 1.9. 


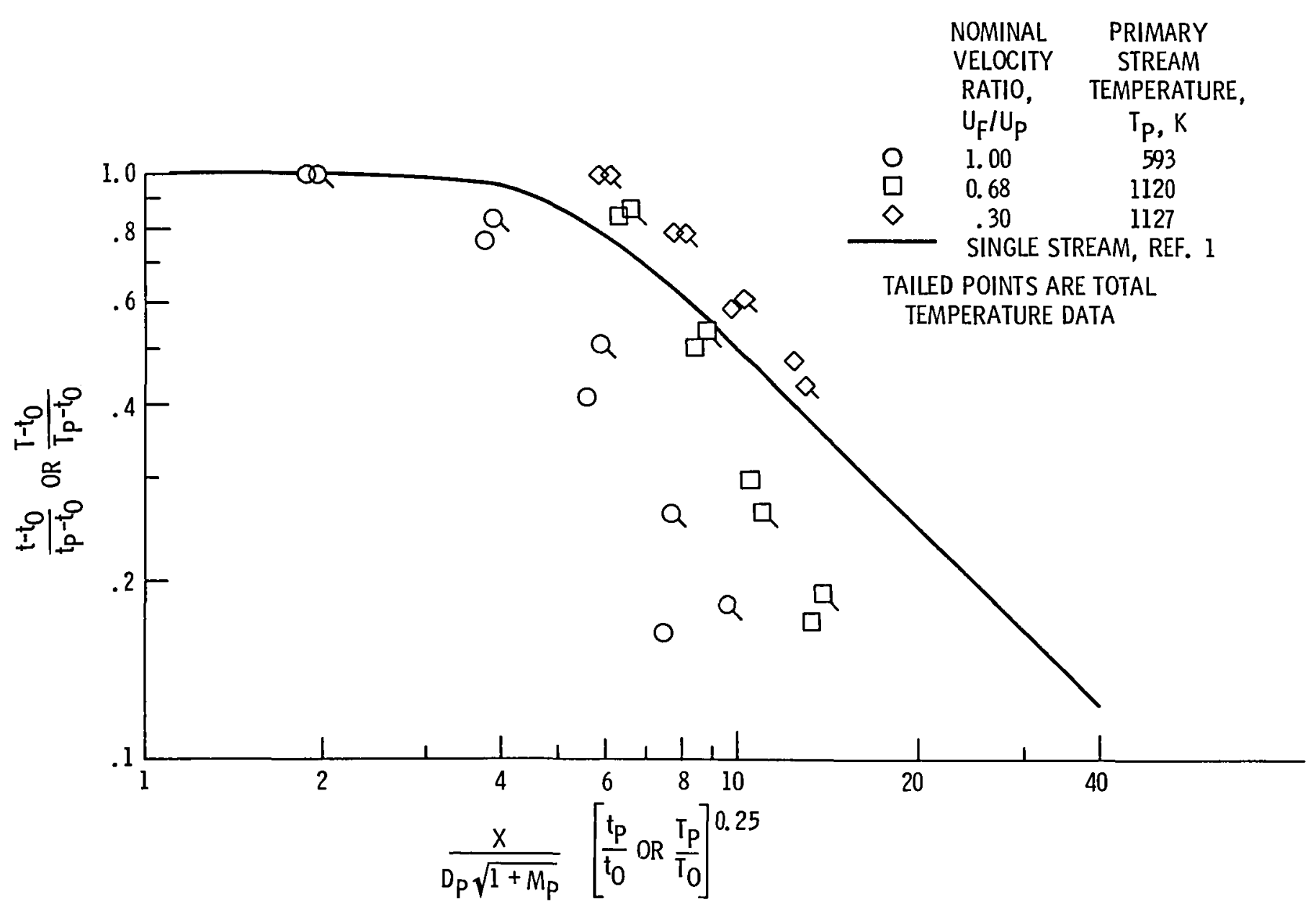

Figure 12. - Jet centerline temperature decay for several $U_{F} / U_{P}$ ratios as a function of axial distance downstream of nozzle exit plane. Ambient fan stream; nozzle AR, 1.9. 


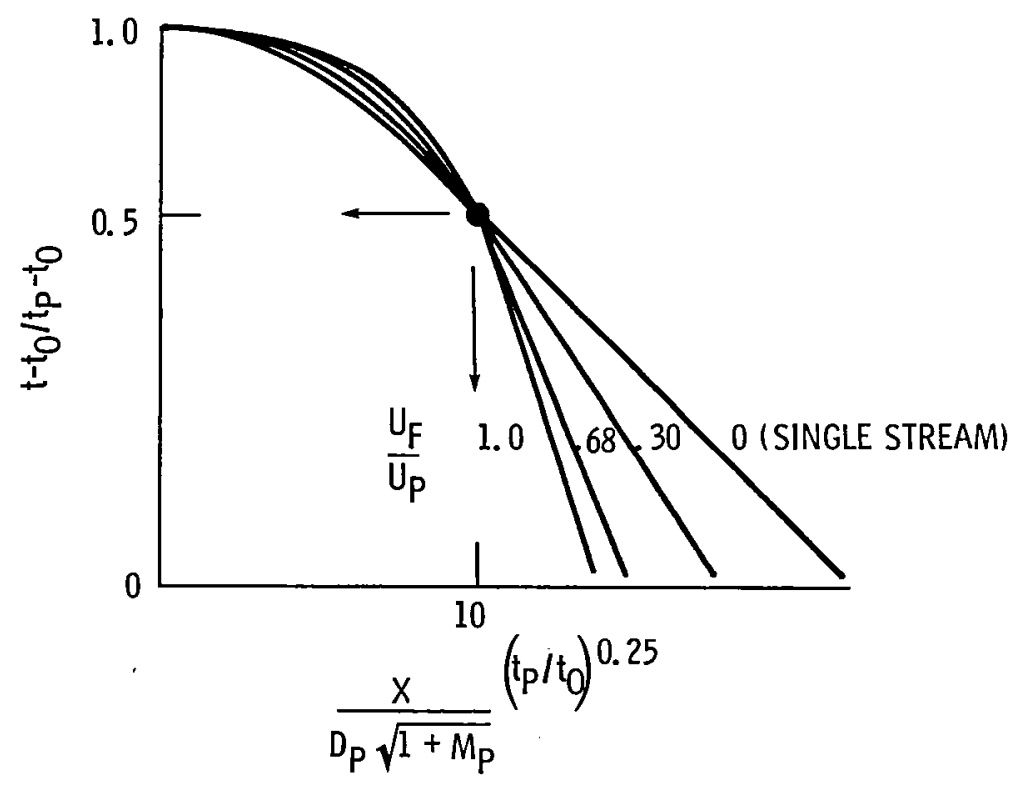

Figure 13. - Normalized jet centerline temperature decay illustrating change in slope with $U_{F} / U_{P}$ ratio. Ambient fan stream; nozzle AR, 1.9. 

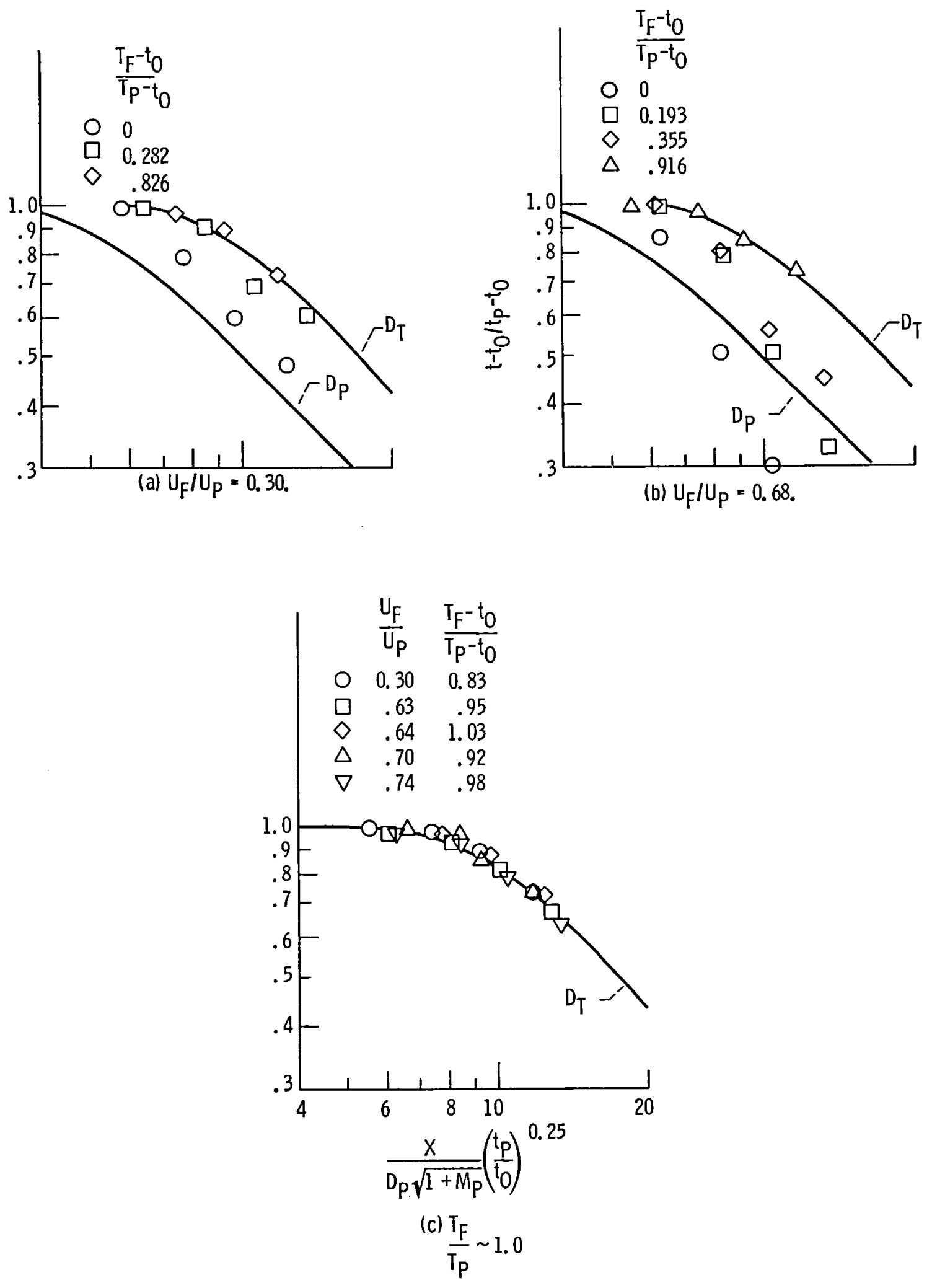

Figure 14. - Effect of fan stream temperature on jet centerline temperature decay. Nozzle AR, 1.9. 


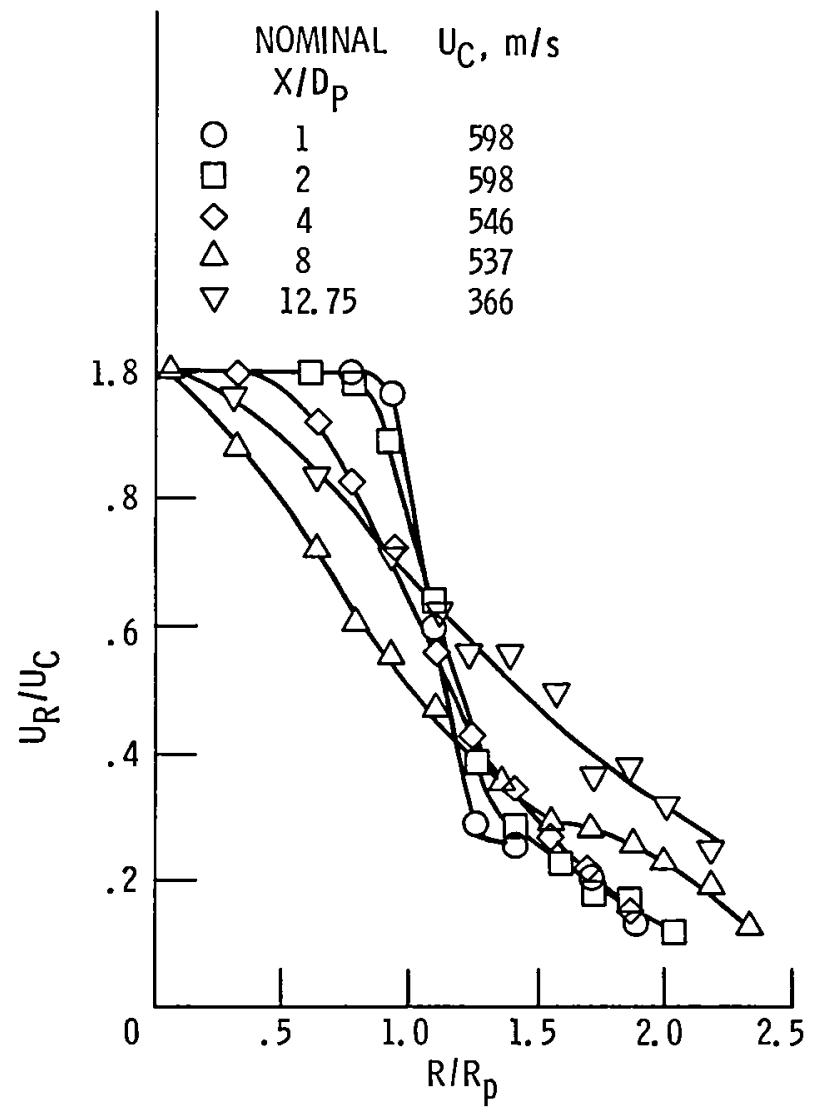

Figure 15. - Typical radial velocity profiles at a $U_{F} / U_{P}$ ratio of 0.30 . Nozzle $A R, 1.9$; $t_{p}$, $984 \mathrm{~K} ; t_{F}, 285 \mathrm{~K} ; U_{P}, 598 \mathrm{~m} / \mathrm{s} ; U_{F}$,

$174 \mathrm{~m} / \mathrm{s}$. 


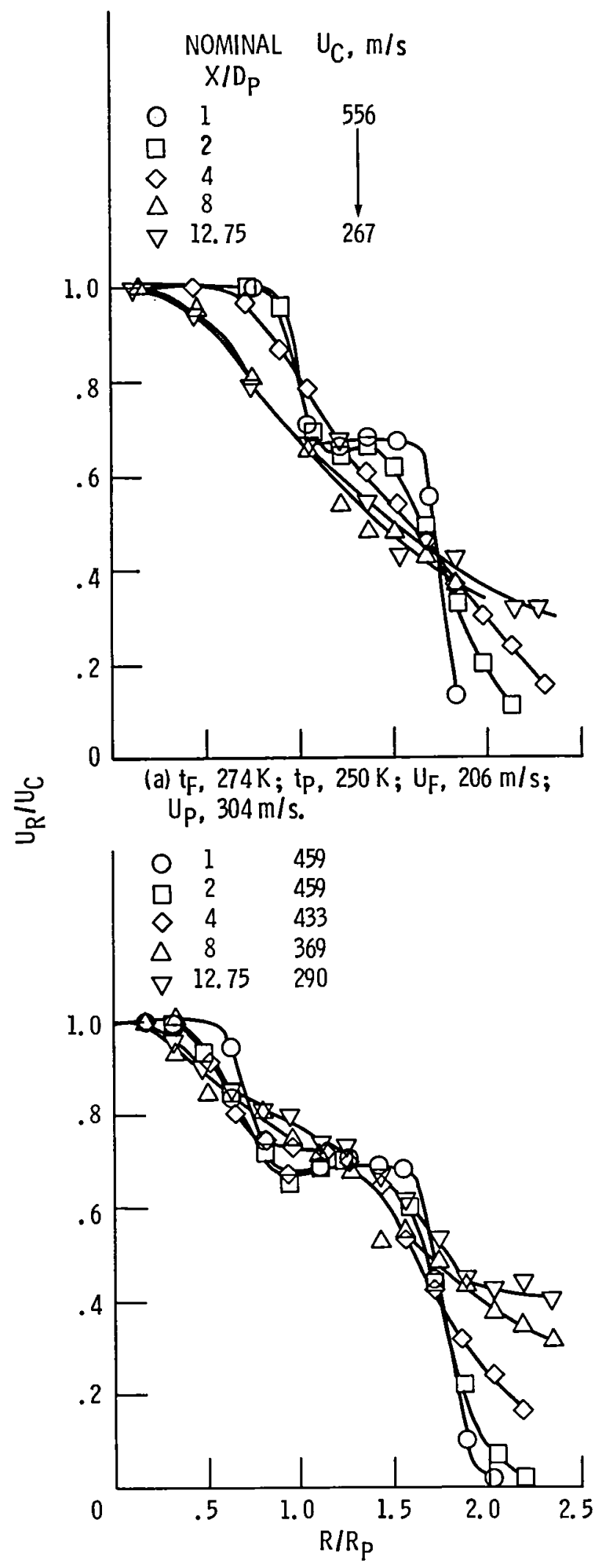

(b) tF, $248 \mathrm{~K}$; tp, $1029 \mathrm{~K}$; $U_{F}, 314 \mathrm{~m} / \mathrm{s}$;

$\mathrm{U}_{\mathrm{p}}, 459 \mathrm{~m} / \mathrm{s}$.

Figure 16. - Typical radial velocity profiles at a $U_{F} / U_{P}$ ratio of 0.68 . Nozzle $A R, 1.9$. 


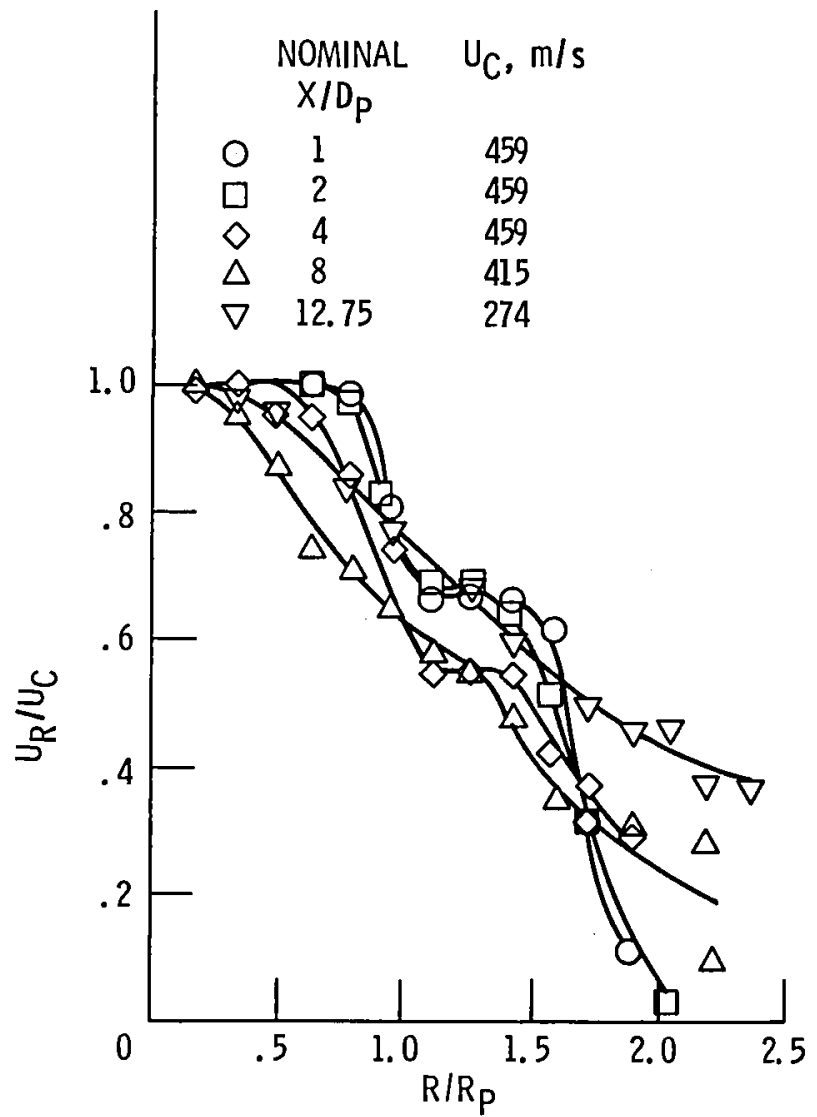

(c) $t_{F}, 545 \mathrm{~K} ; t_{p}, 1050 \mathrm{~K} ; U_{F}, 314 \mathrm{~m} / \mathrm{s}$; Up, $459 \mathrm{~m} / \mathrm{s}$.

Figure 16. - Concluded.

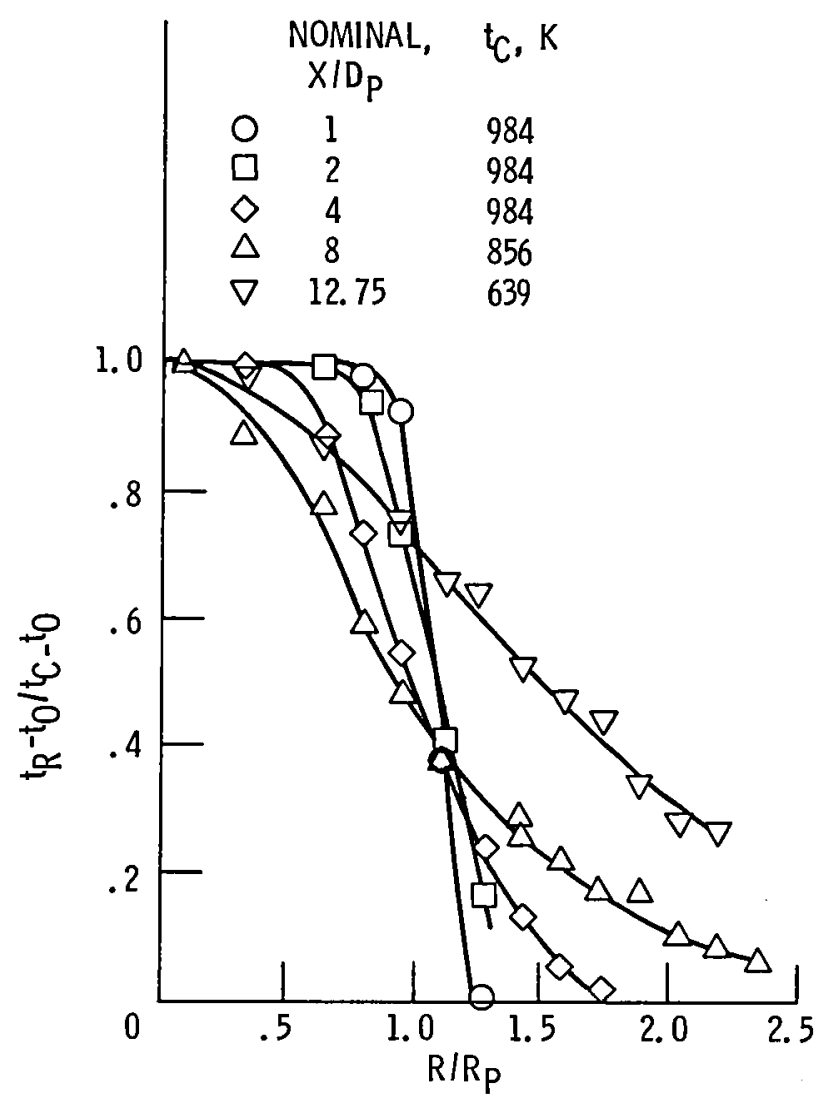

Figure 17. - Typical radial temperature profiles at a $U_{F} / U_{P}$ ratio of 0.30 . Nozzel AR, 1. 9; $t_{p}, 984 \mathrm{~K}, \mathrm{t}_{\mathrm{F}}, 285 \mathrm{~K} ; \mathrm{U}_{\mathrm{p}}, 598 \mathrm{~m} / \mathrm{s}$; $\mathrm{U}_{\mathrm{F}}, 174 \mathrm{~m} / \mathrm{s}$. 


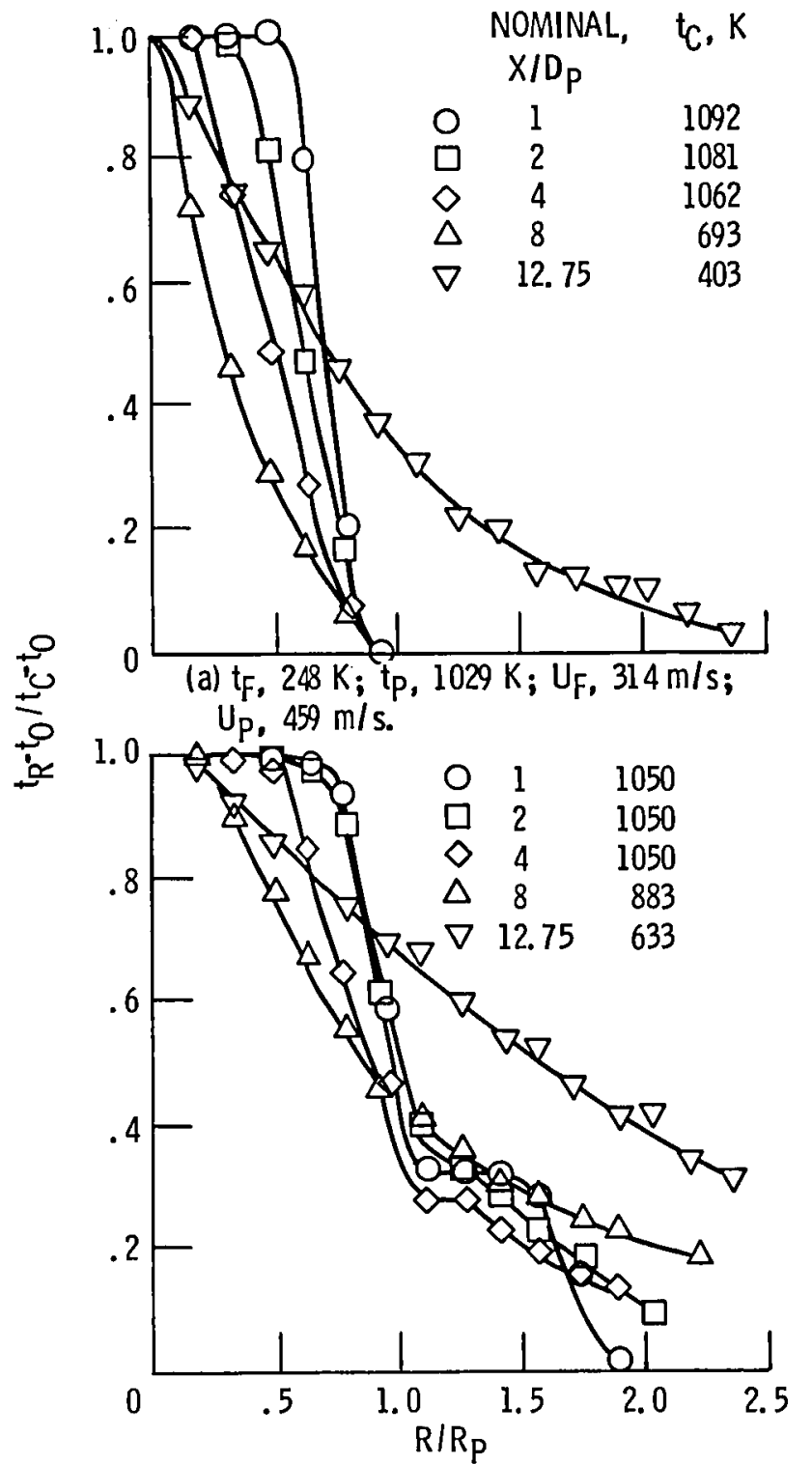

(b) $t_{F}, 545 \mathrm{~K} ; t_{p}, 1050 \mathrm{~K} ; u_{F}, 314 \mathrm{~m} / \mathrm{s}$; $U_{p}, 459 \mathrm{~m} / \mathrm{s}$.

Figure 18. - Typical radial temperature profiles at a $U_{F} / U_{P}$ ratio of 0.68 . Nozzle $A R, 1.9$.

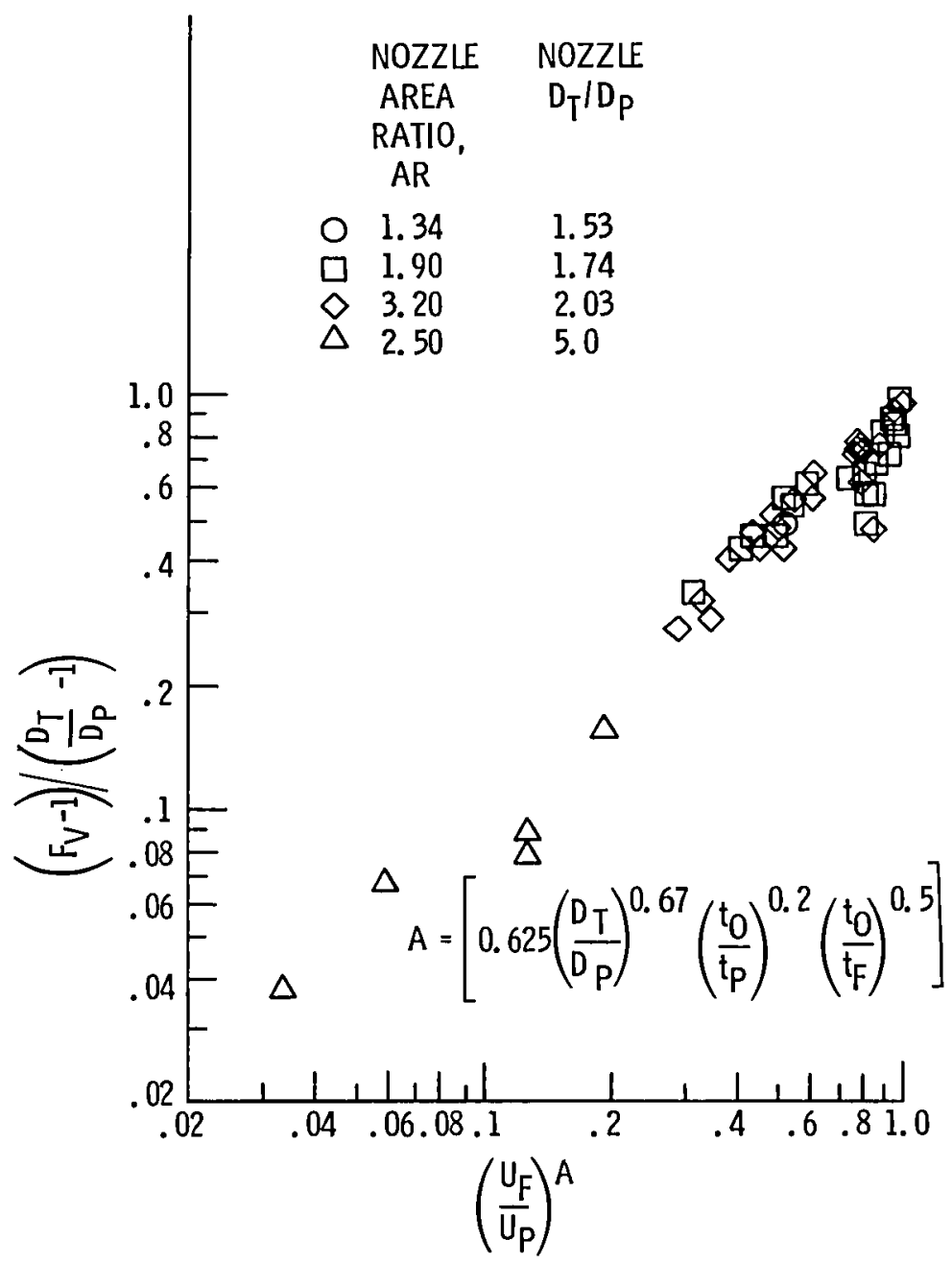

Figure 19. - Correlation parameter $F_{y}$ as a function of nozzle size and jet operating conditions. 


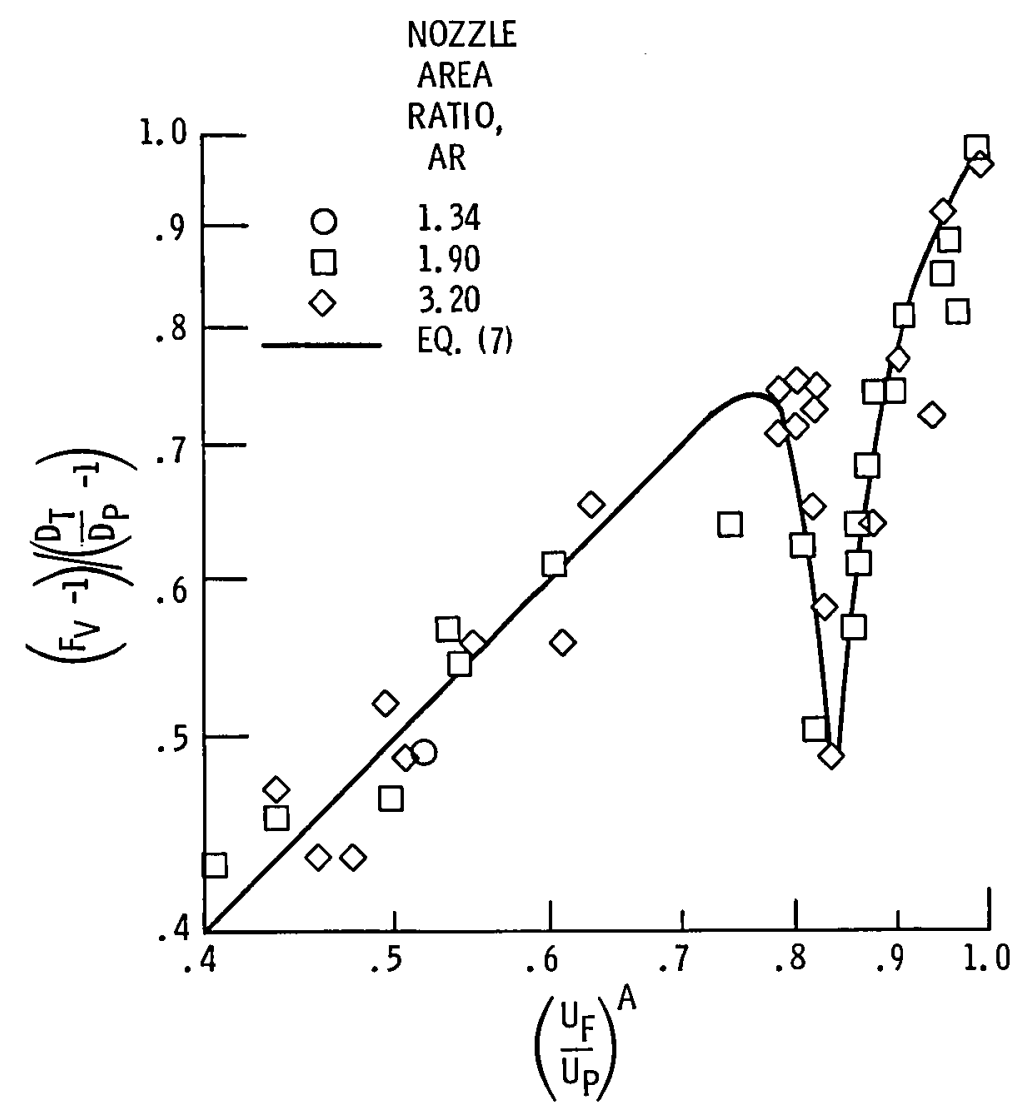

Figure 20. - Comparison of measured correlation parameter $F_{V}$ values with equation (7) prediction curve.

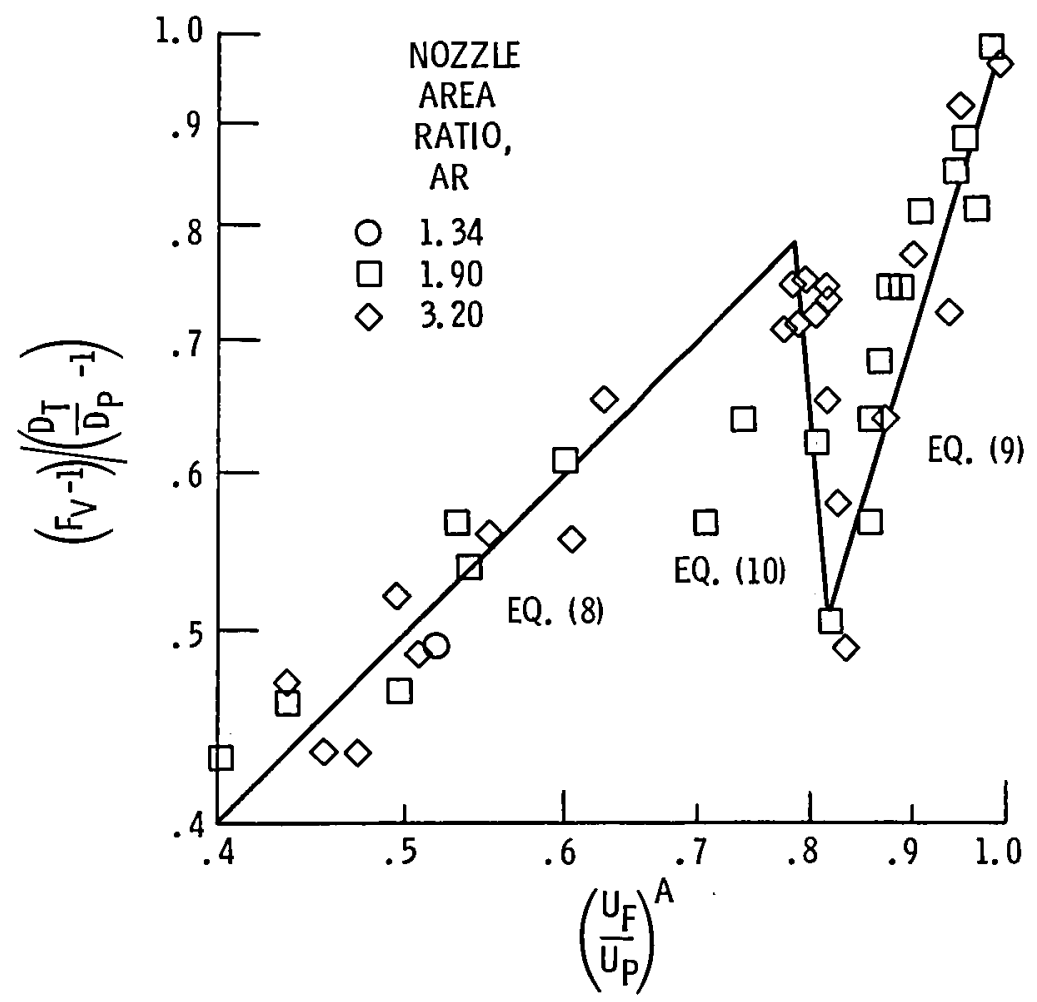

Figure 21. - Comparison of measured correlation parameter $F_{V}$ values with three-equation prediction curves. 


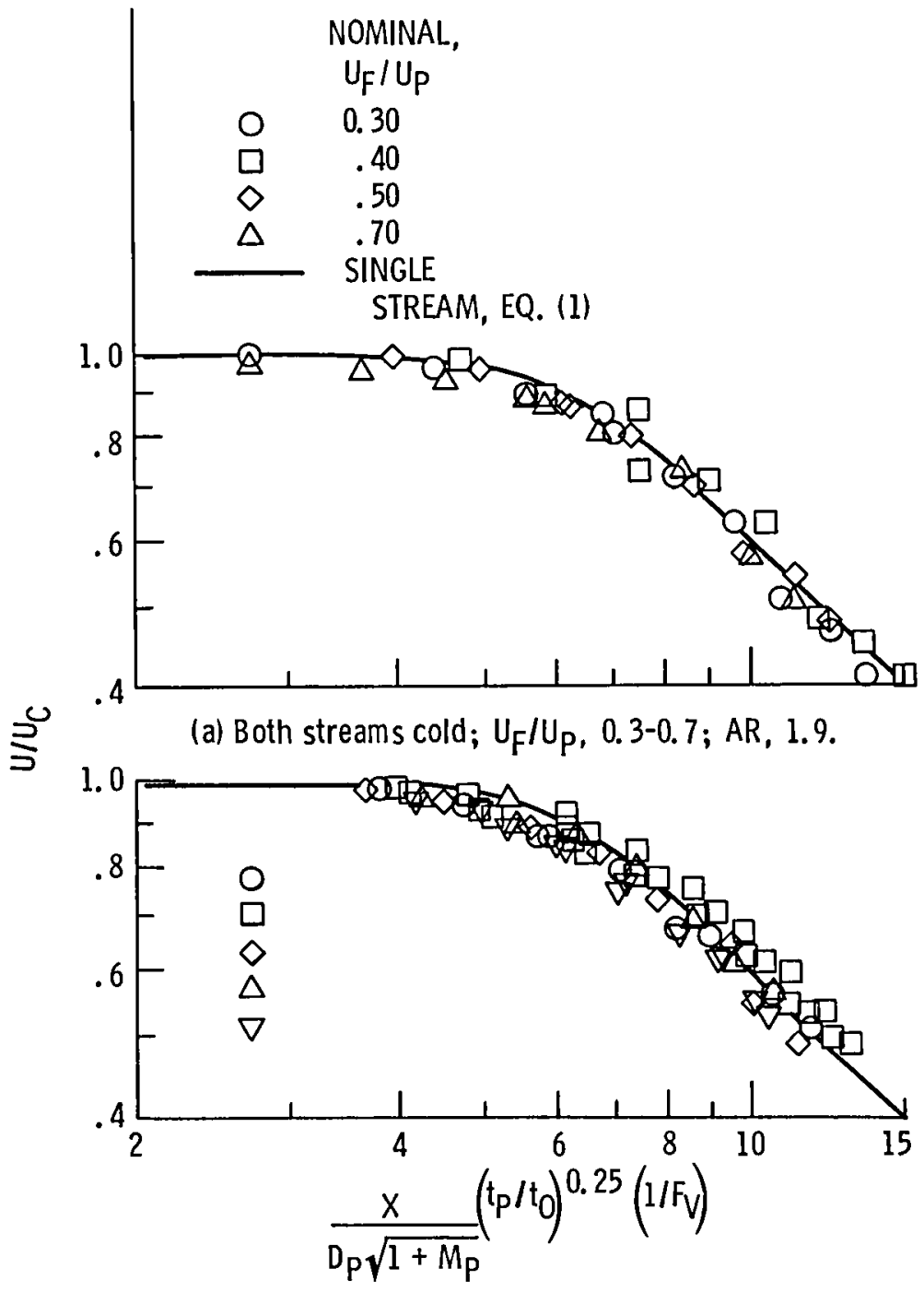

(b) Both streams cold; $U_{F} / U_{P}, 0.7-1.0 ; A R, 1.9$.

Figure 22. - Correlated jet centerline velocity decay.

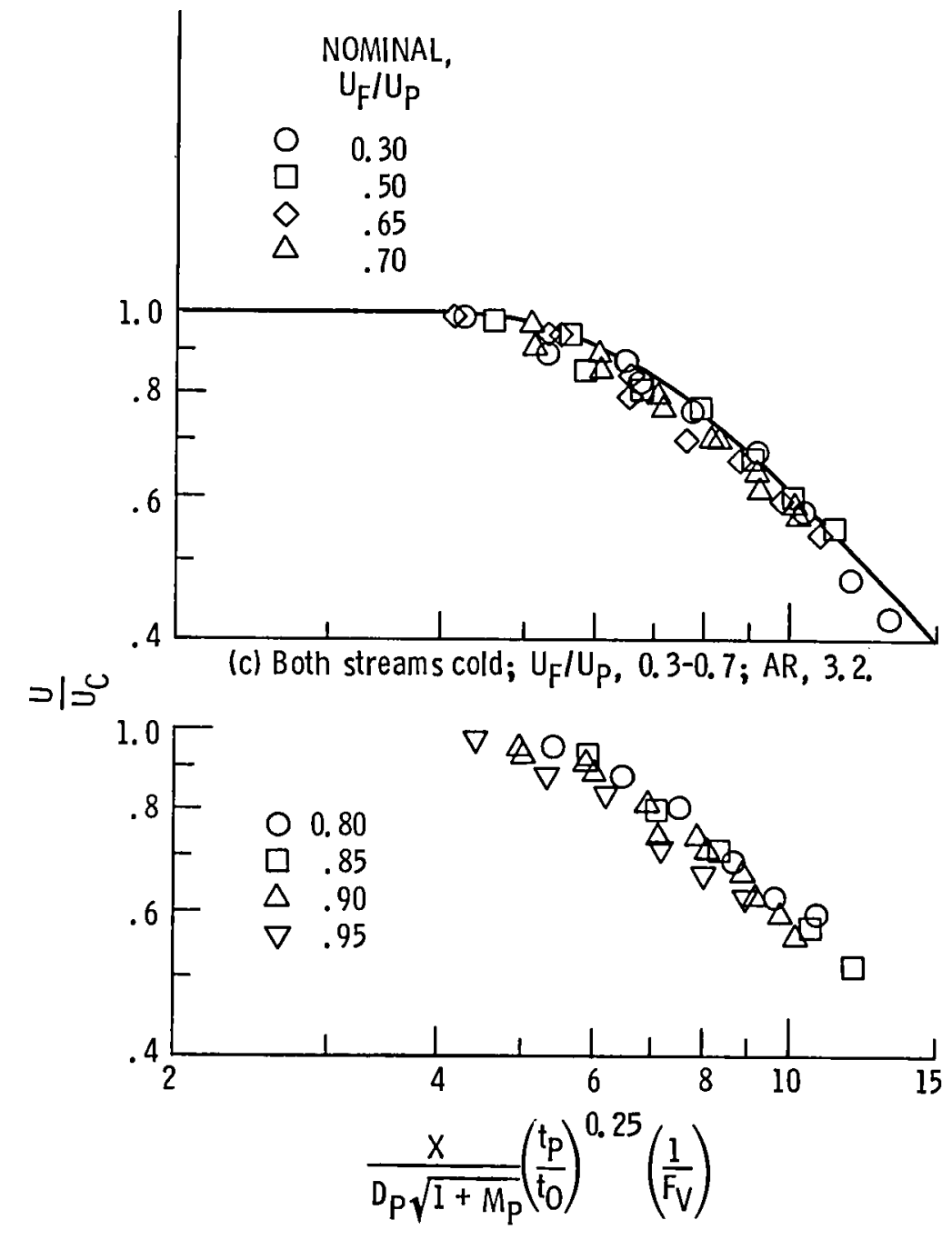

(d) Both streams cold; $U_{F} / U_{P}, 0.7-1.0 ; A R, 3.2$

Figure 22. - Continued. 


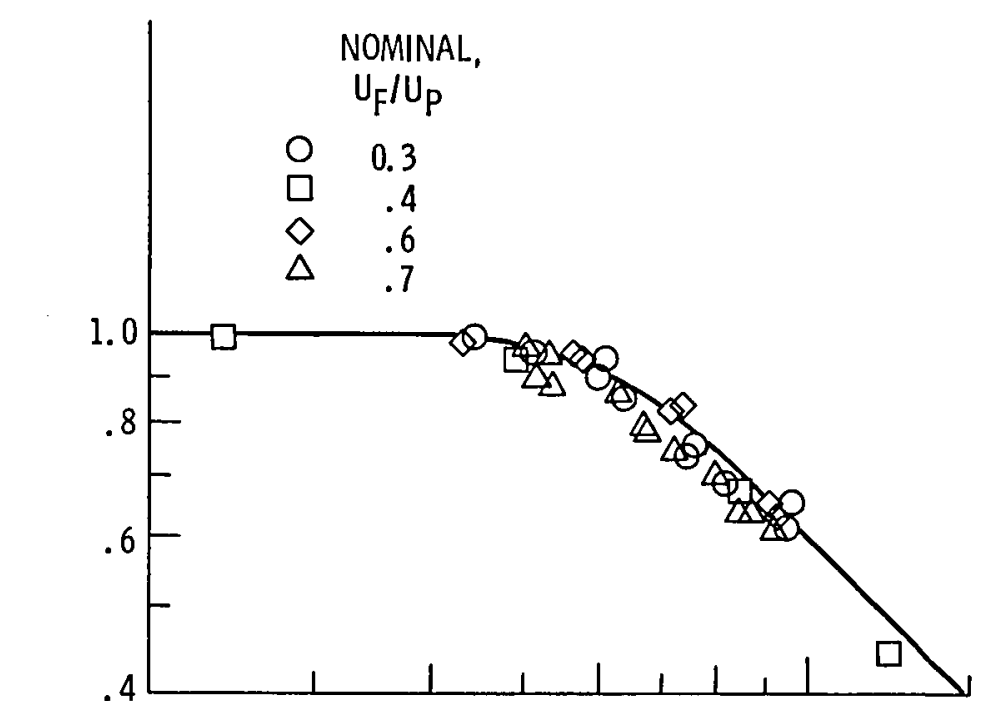

(e) Heated flow; $U_{F} / U_{P}, 0.3-0.7 ; A R, 1.9$.

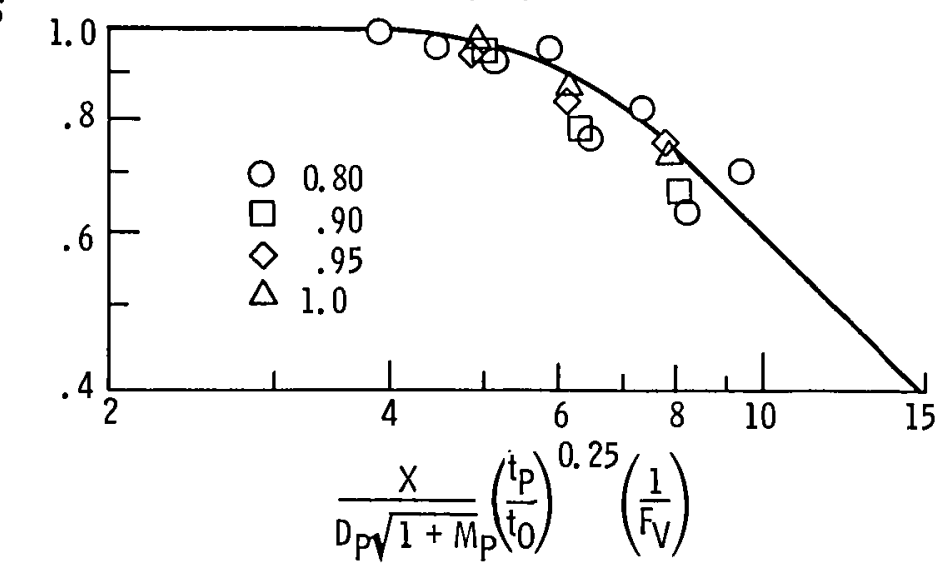

(f) Heated flow; $U_{F} / U_{p}, 0.7-1.0 ; A R, 1.9$.

Figure 22. - Continued.

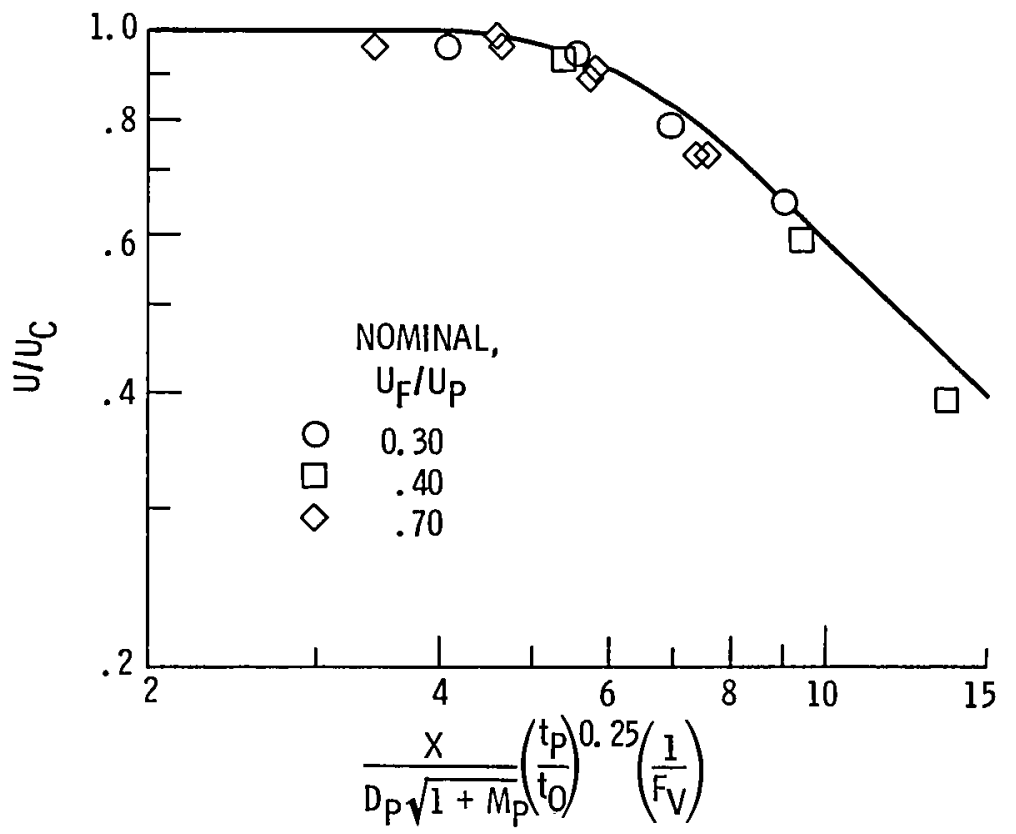

(g) Heated flow; UF $/ U_{p}, 0.3-0.7 ; A R, 3.2$.

Figure 22. - Concluded. 


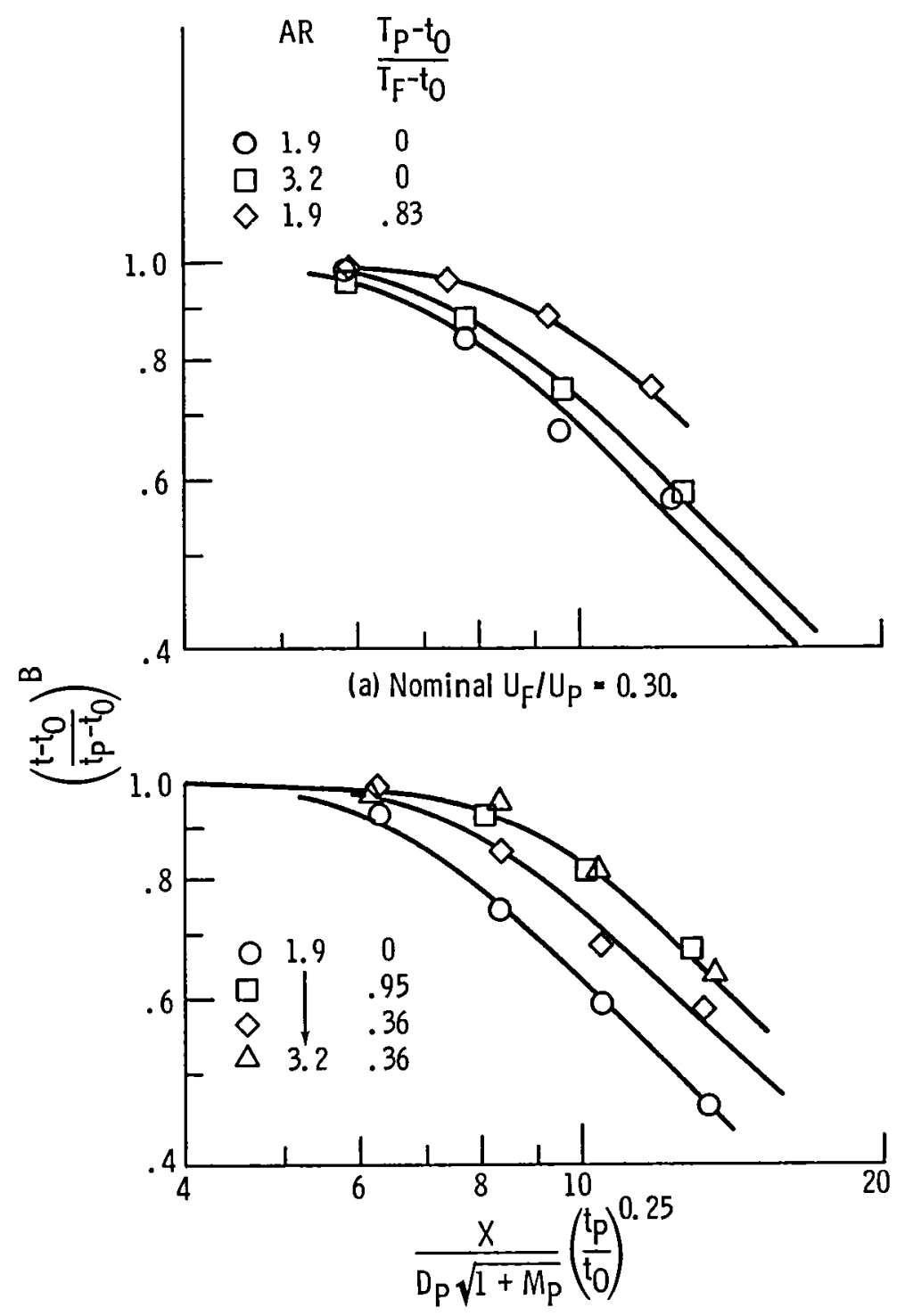

(b) Nominal $U_{F} / U_{P}=0.68$.

Figure 23. - Two-stream centerline temperature decay curve slope modification using exponent $B$. 


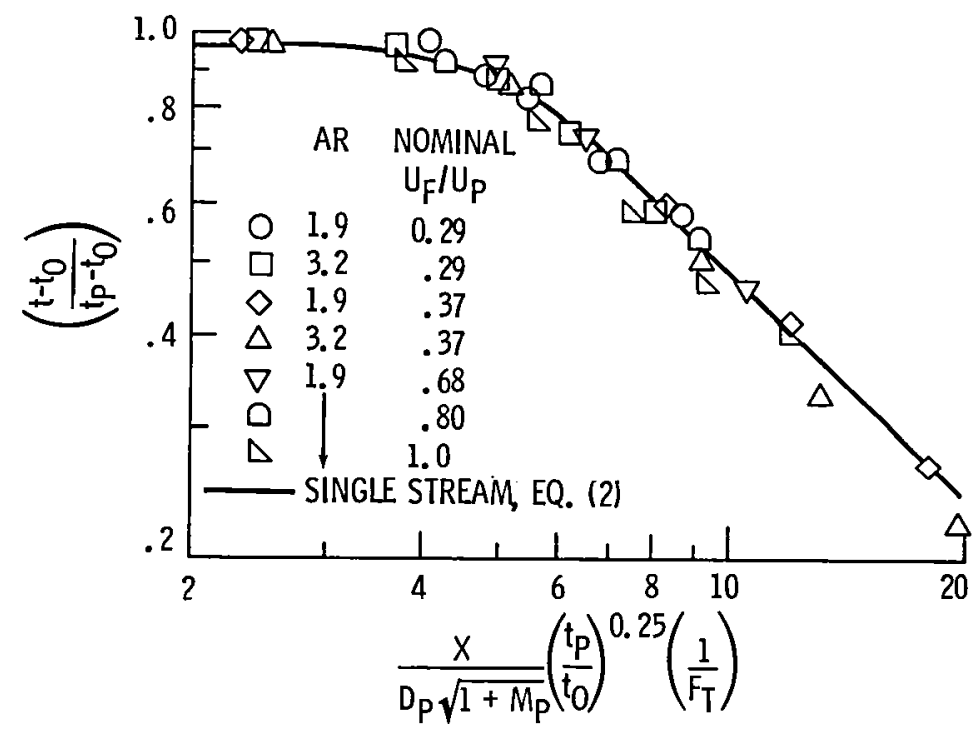

(a) Cold fan stream.

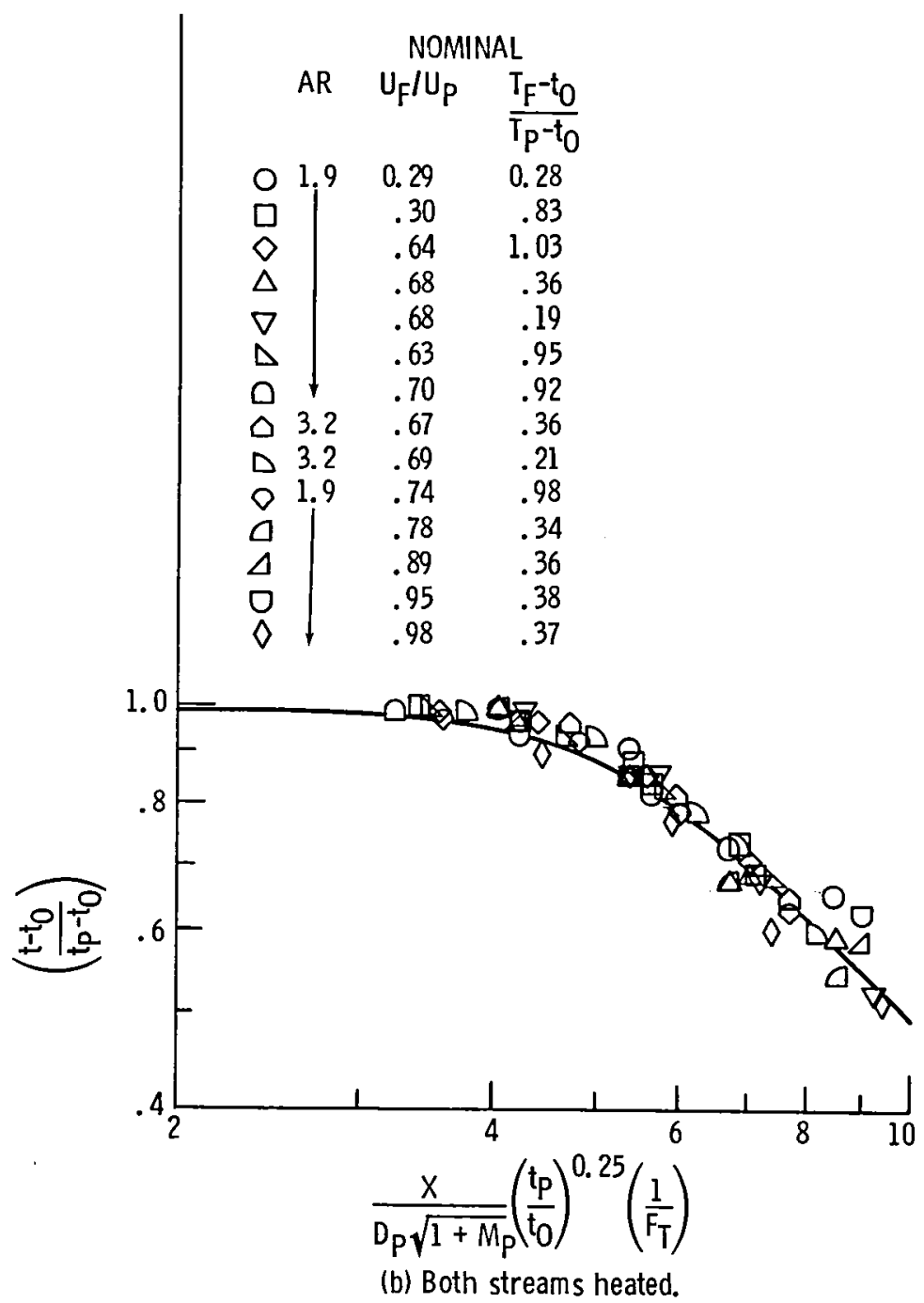

Figure 24. - Correlated jet centerline static temperature decay. 


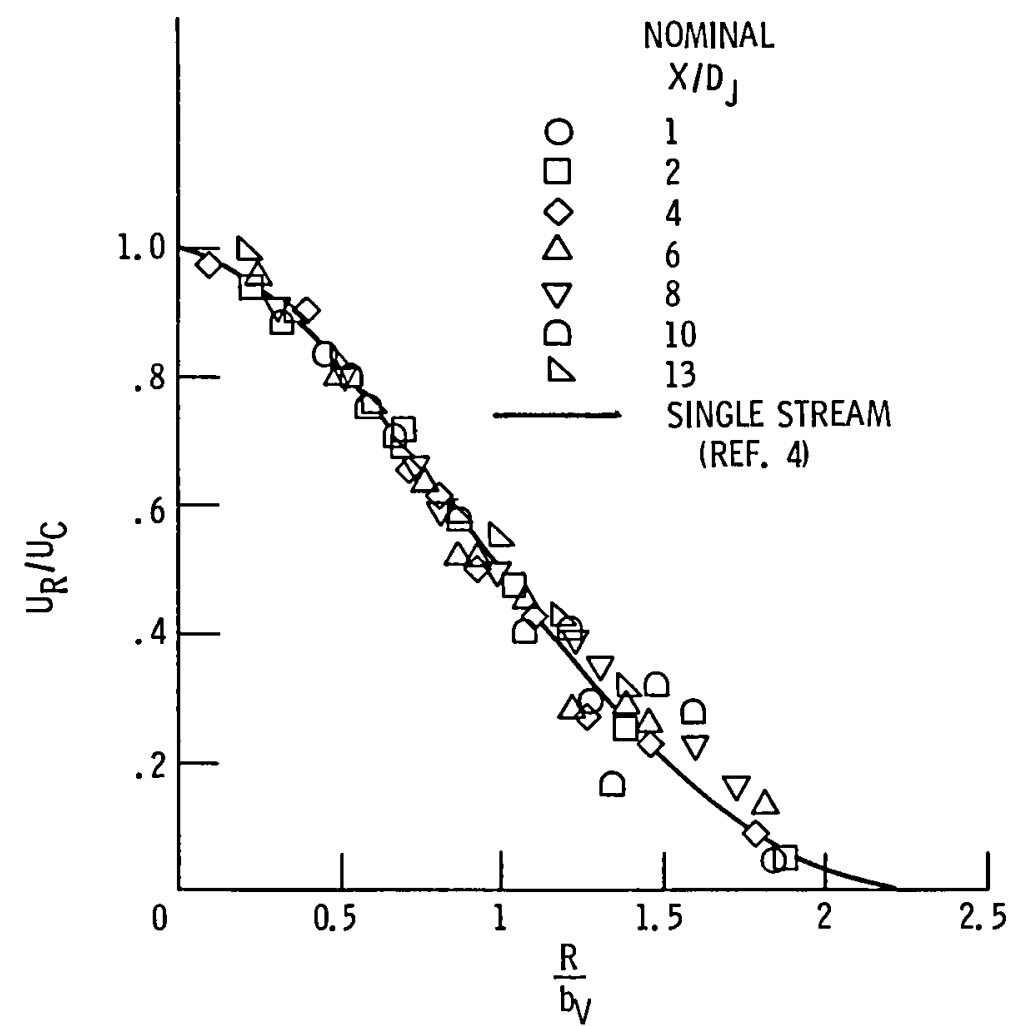

Figure 25. - Typical normalized single-stream radial velocity profiles. $M_{J}, 0.97 ; U_{J}, 595 \mathrm{~m} / \mathrm{s}, t_{\mathrm{J}}, 986 \mathrm{~K} ; \mathrm{T}_{\mathrm{J}}$, $1114 \mathrm{~K}$.

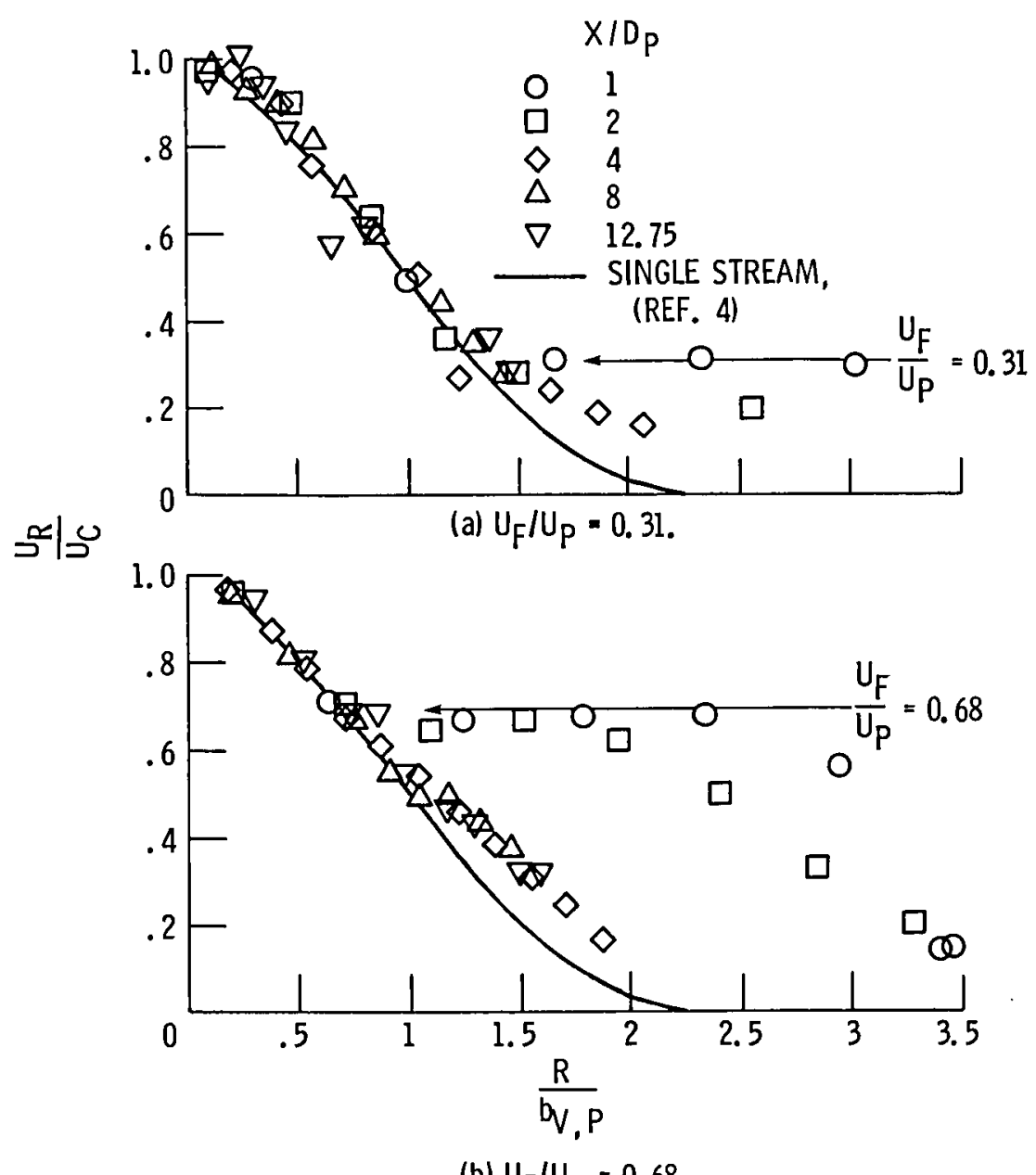

(b) $U_{F} / U_{P}=0.68$.

Figure 26. - Typical normalized two-stream radial velocity profiles. Both streams cold. 

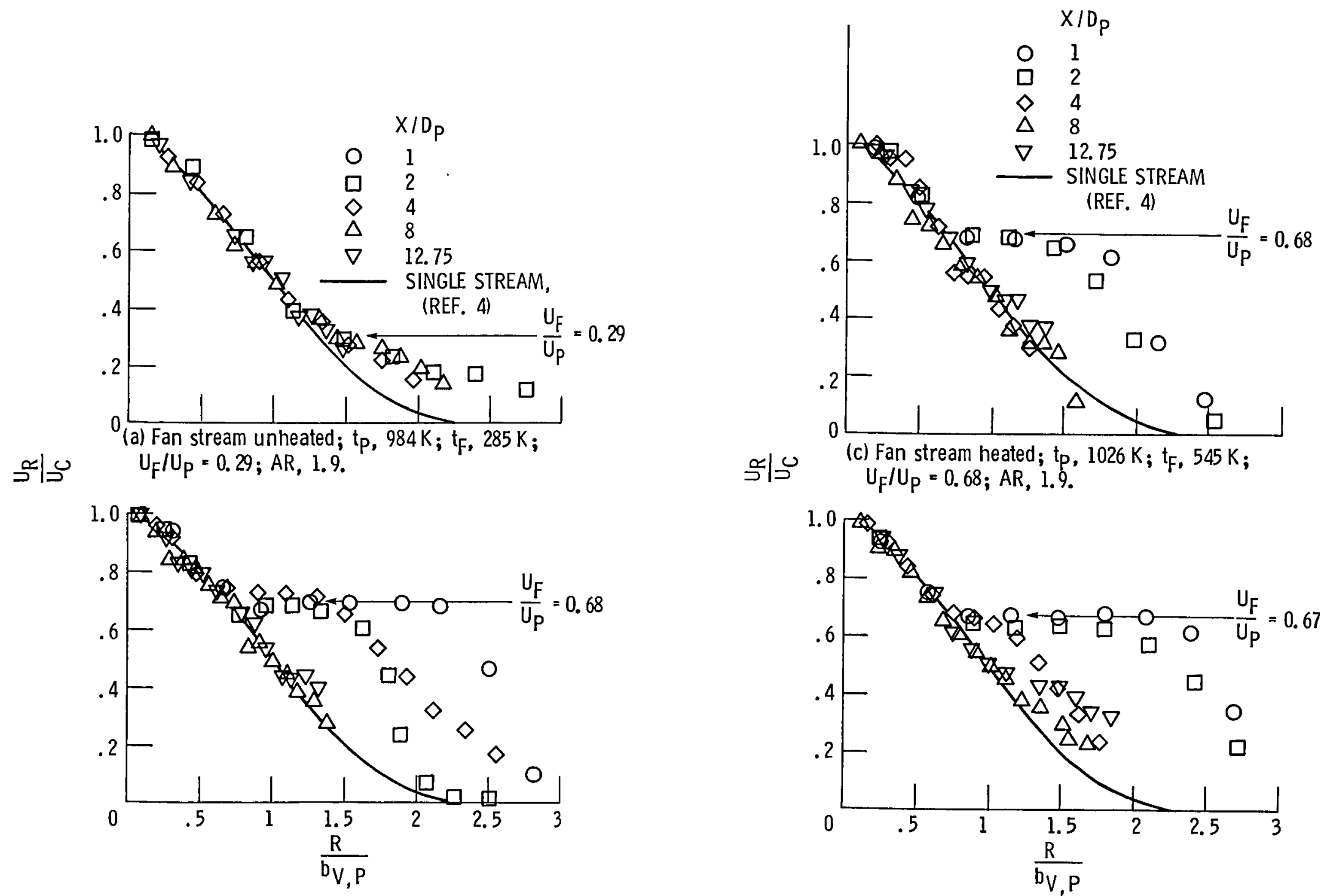

(b) Fan stream unheated; $t_{p}, 1029 \mathrm{~K}$; $t_{p}, 248 \mathrm{~K}$; $U_{F} / U_{P}=0.68 ; A R, 1.9$.

Figure 27. - Typical normalized two-stream radial velocity profiles. Heated primary stream.

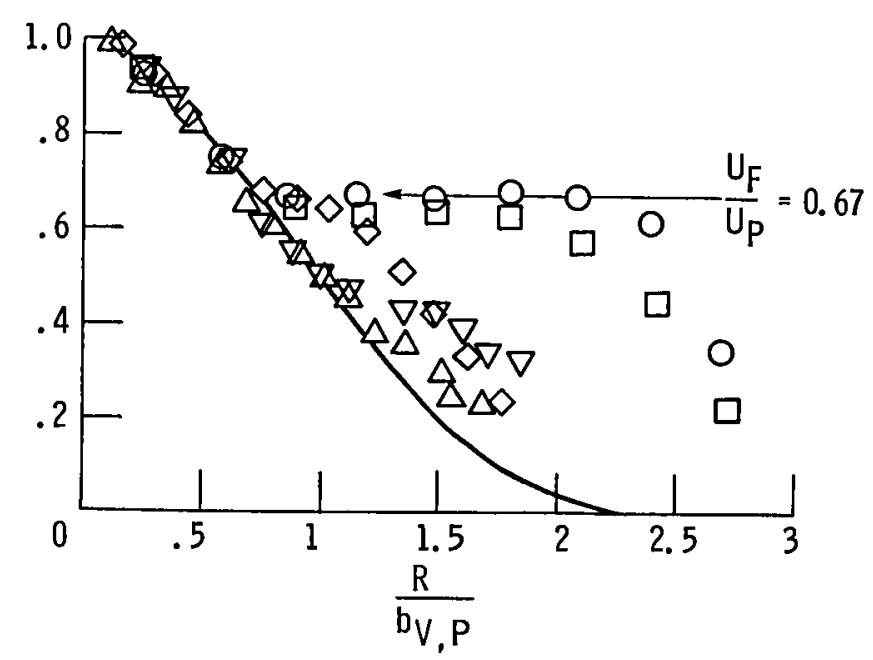

(d) Fan stream heated; $t_{p}, 1028 \mathrm{~K} ; t_{F_{0}} 542 \mathrm{~K}$; $U_{F} / U_{P}=0.67 ; A R, 3.2$.

Figure 27. - Concluded. 


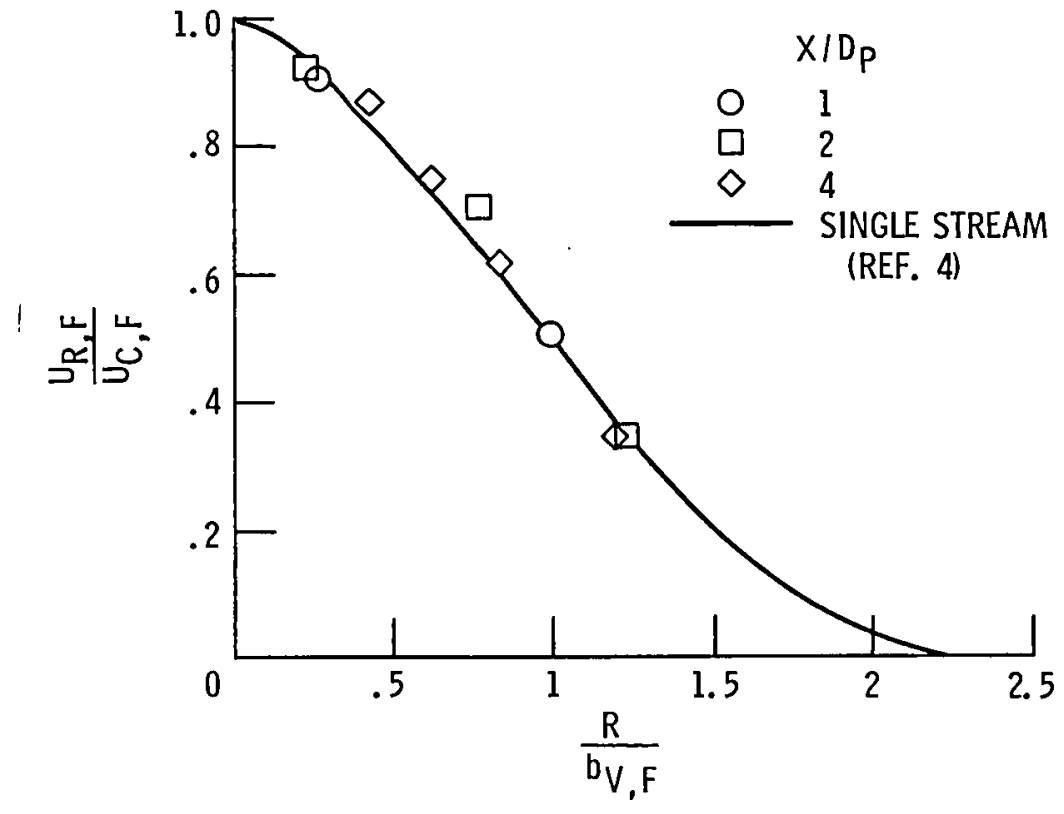

Figure 28. - Typical normalized fan stream radial velocity profile. $U_{F} / U_{P}=0.67$; both streams heated; $t_{P}$, $1028 \mathrm{~K} ; t_{F}, 542 \mathrm{~K} ; A R, 3.2$

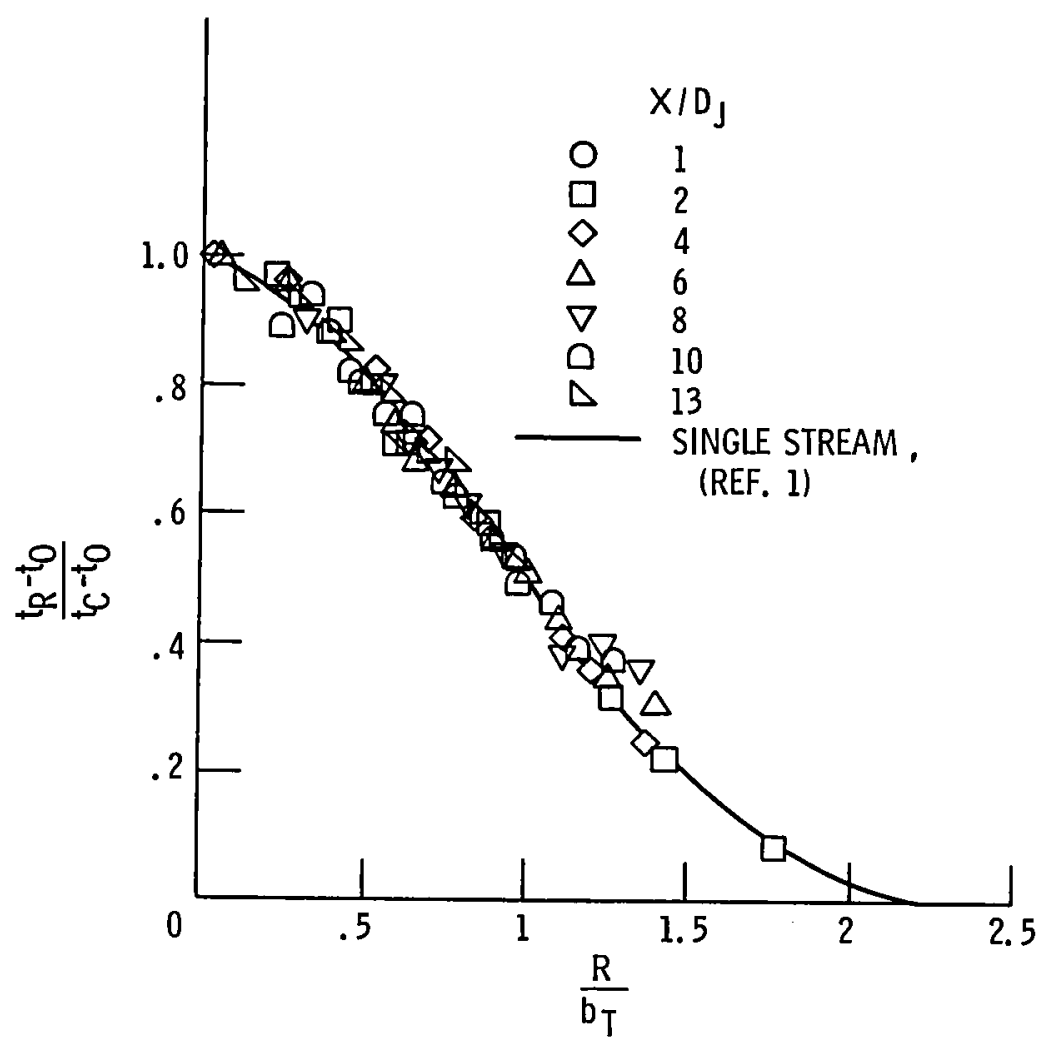

Figure 29. - Typical normalized single-stream radial temperature profiles. $M_{J}, 0.97 ; U_{J}, 595 \mathrm{~m} / \mathrm{s} ; t_{J}, 986 \mathrm{~K}$; $\mathrm{T}_{\mathrm{J}}, 1114 \mathrm{~K}$. 


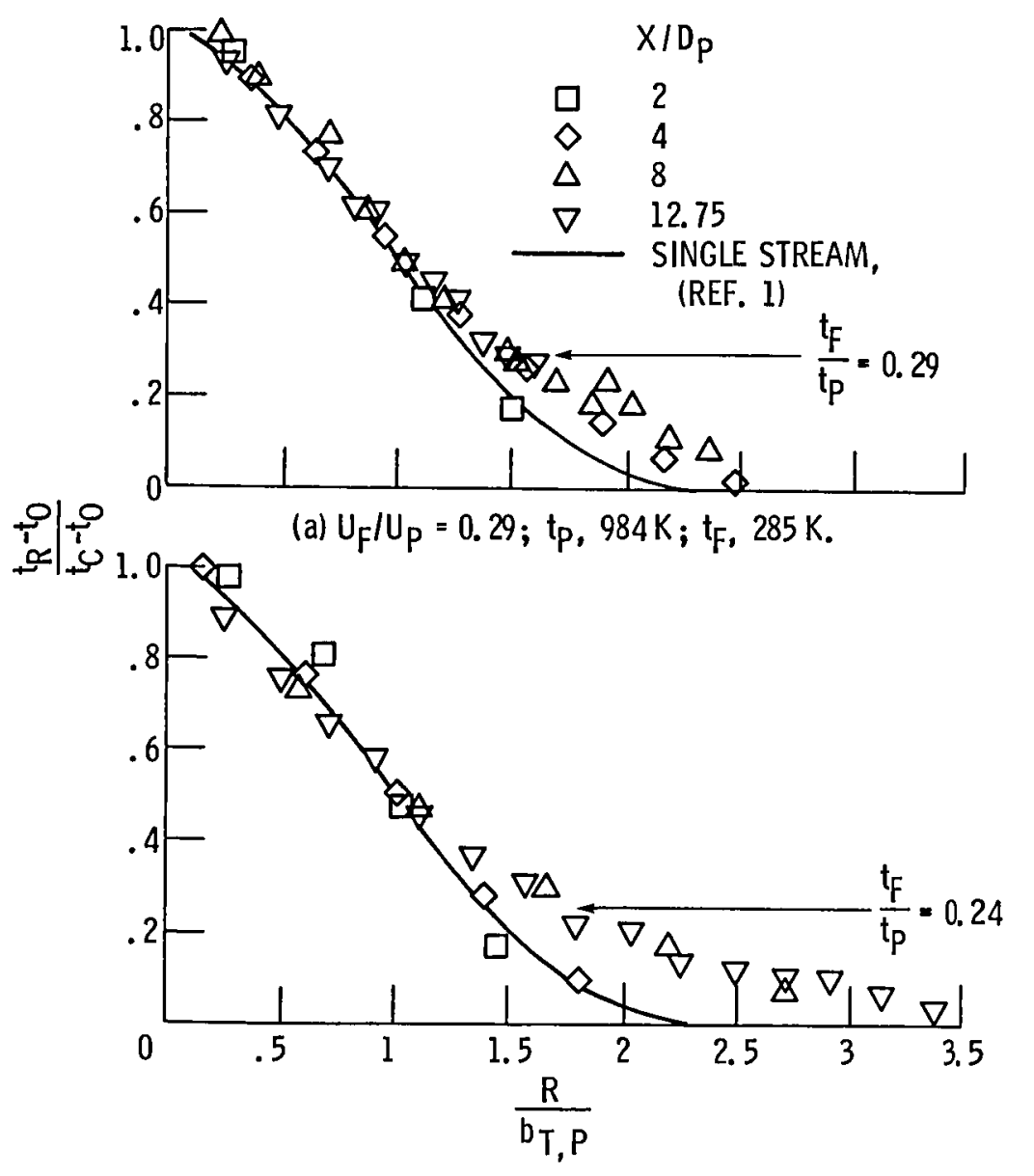

(b) $U_{F} / U_{P}=0.68 ; t_{P}, 1029 \mathrm{~K} ; t_{F}, 247 \mathrm{~K}$.

Figure 30. - Typical normalized two-stream radial temperature profiles. AR, 1.9; cold fan stream.

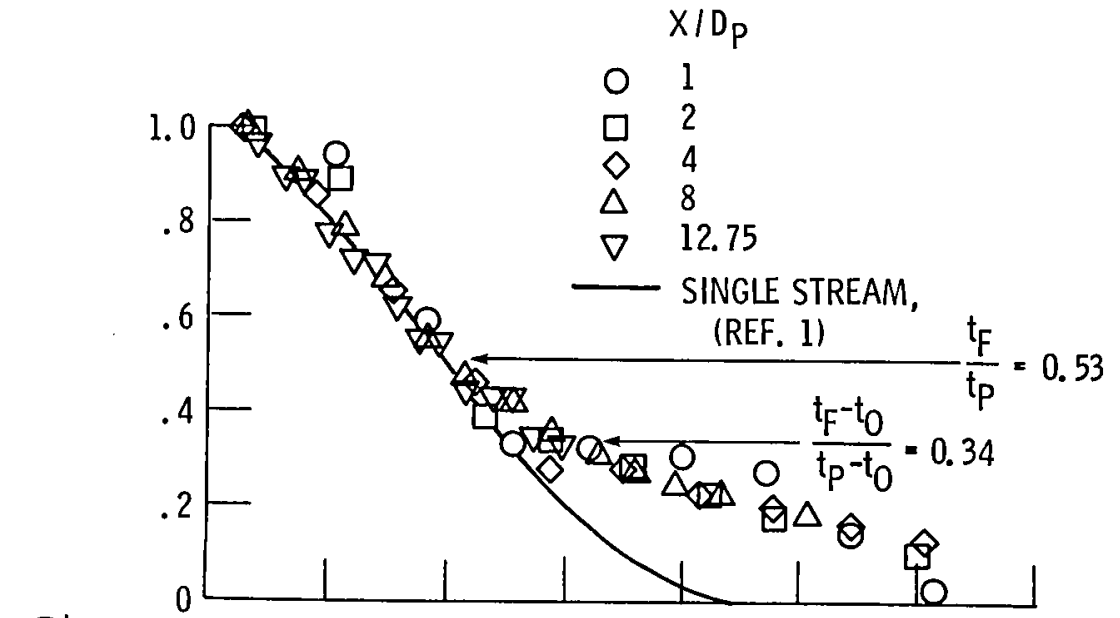

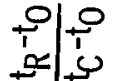

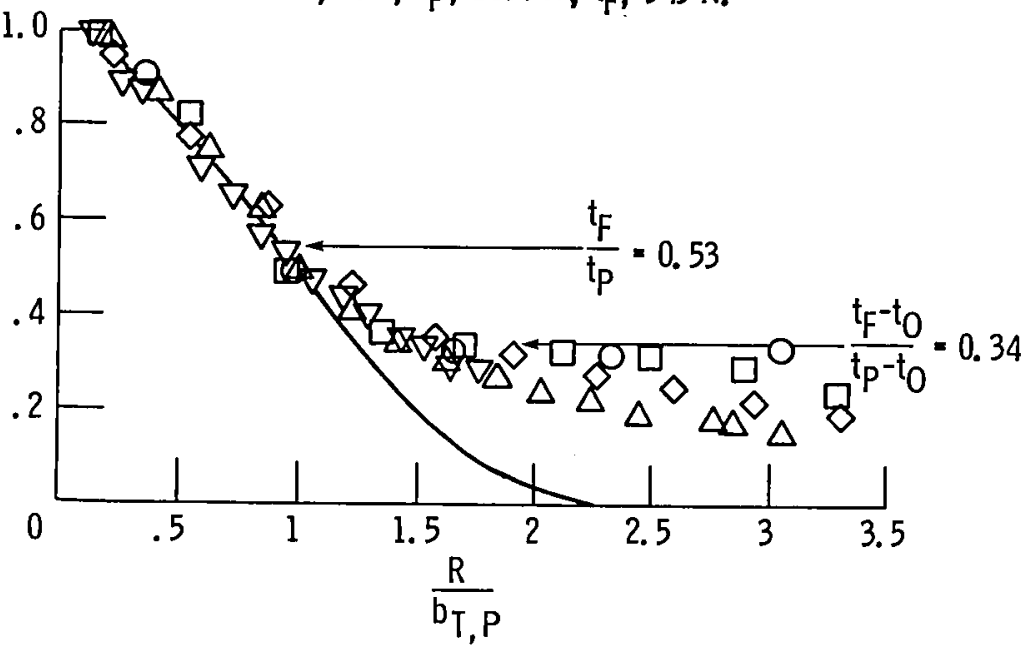

(b) AR, 3.2; $t_{P}, 1028 \mathrm{~K}$; $t_{F}, 542 \mathrm{~K}$.

Figure 31. - Typical normalized two-stream radial temperature profiles. Both streams heated. Nominal $U_{F} / U_{P}=0.68$. 


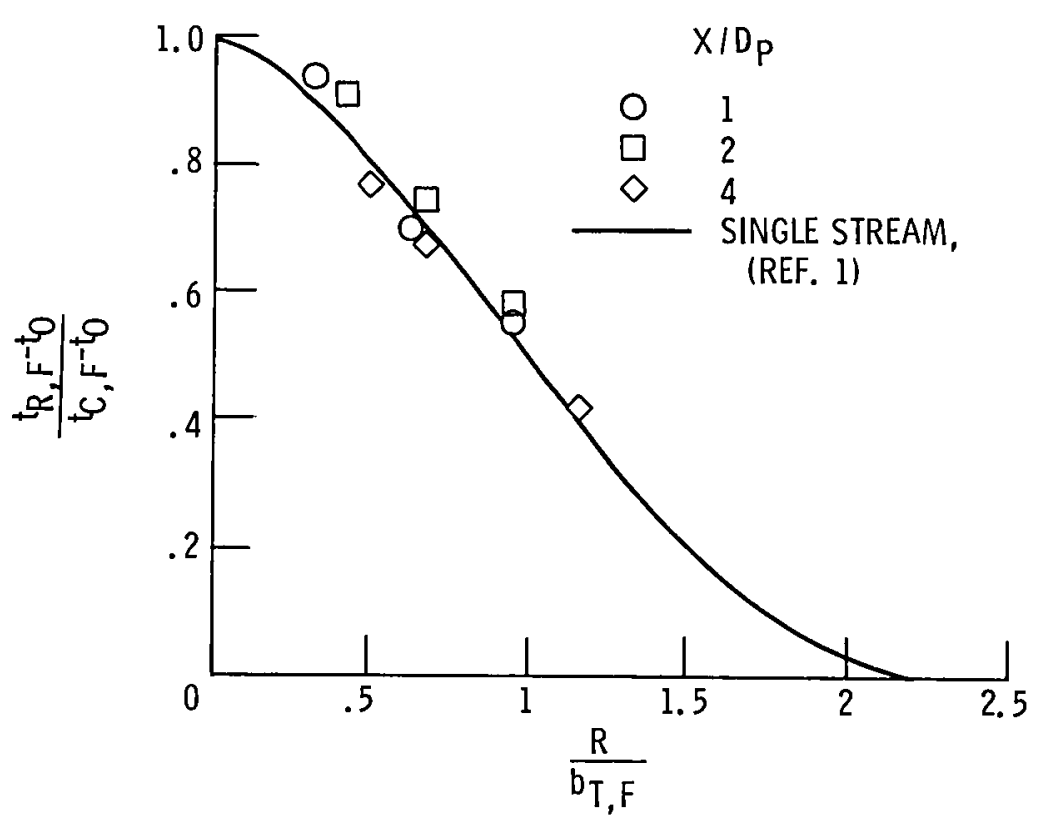

Figure 32. - Typical normalized fan stream radial temperature profile. Both streams heated; $t_{p}, 1028 \mathrm{~K} ; t_{F}$, $542 K ; U_{F} / U_{P}=0.68 ; A R, 3.2$

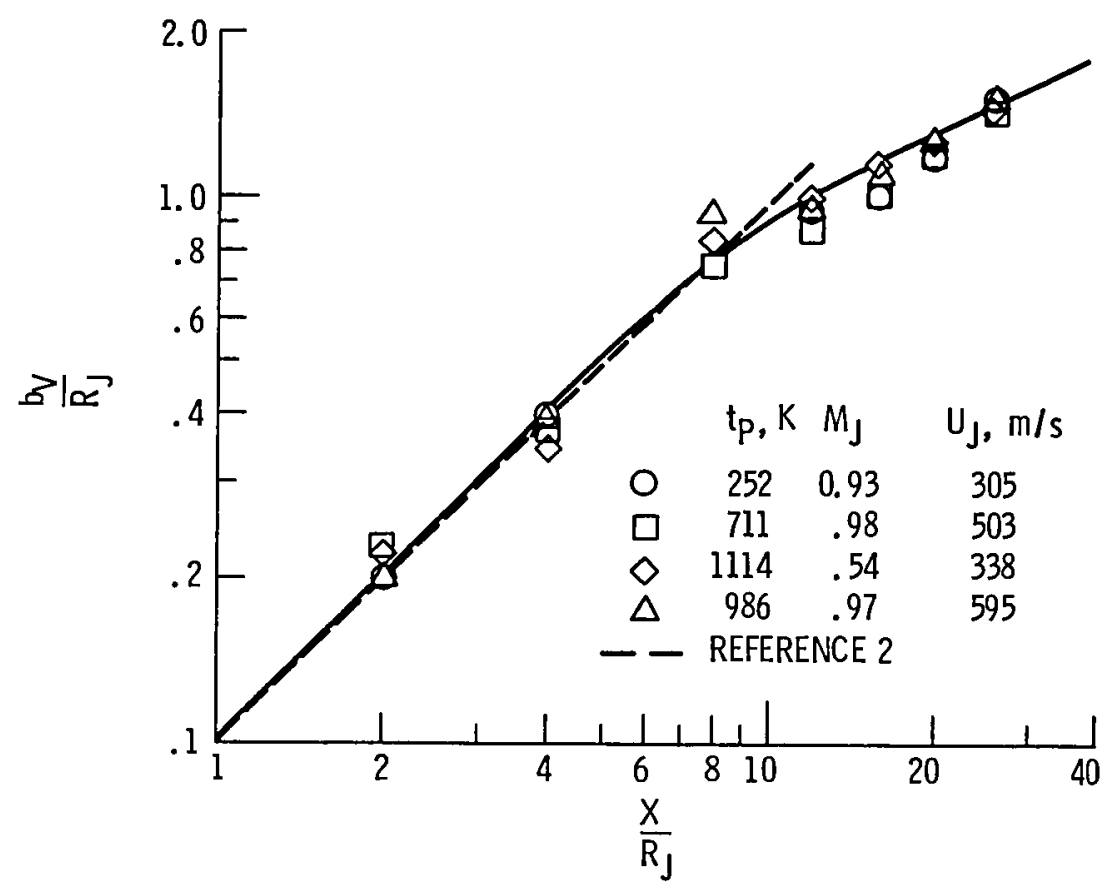

Figure 33. - Jet plume velocity radial spreading characteristics for single-stream nozzle. 


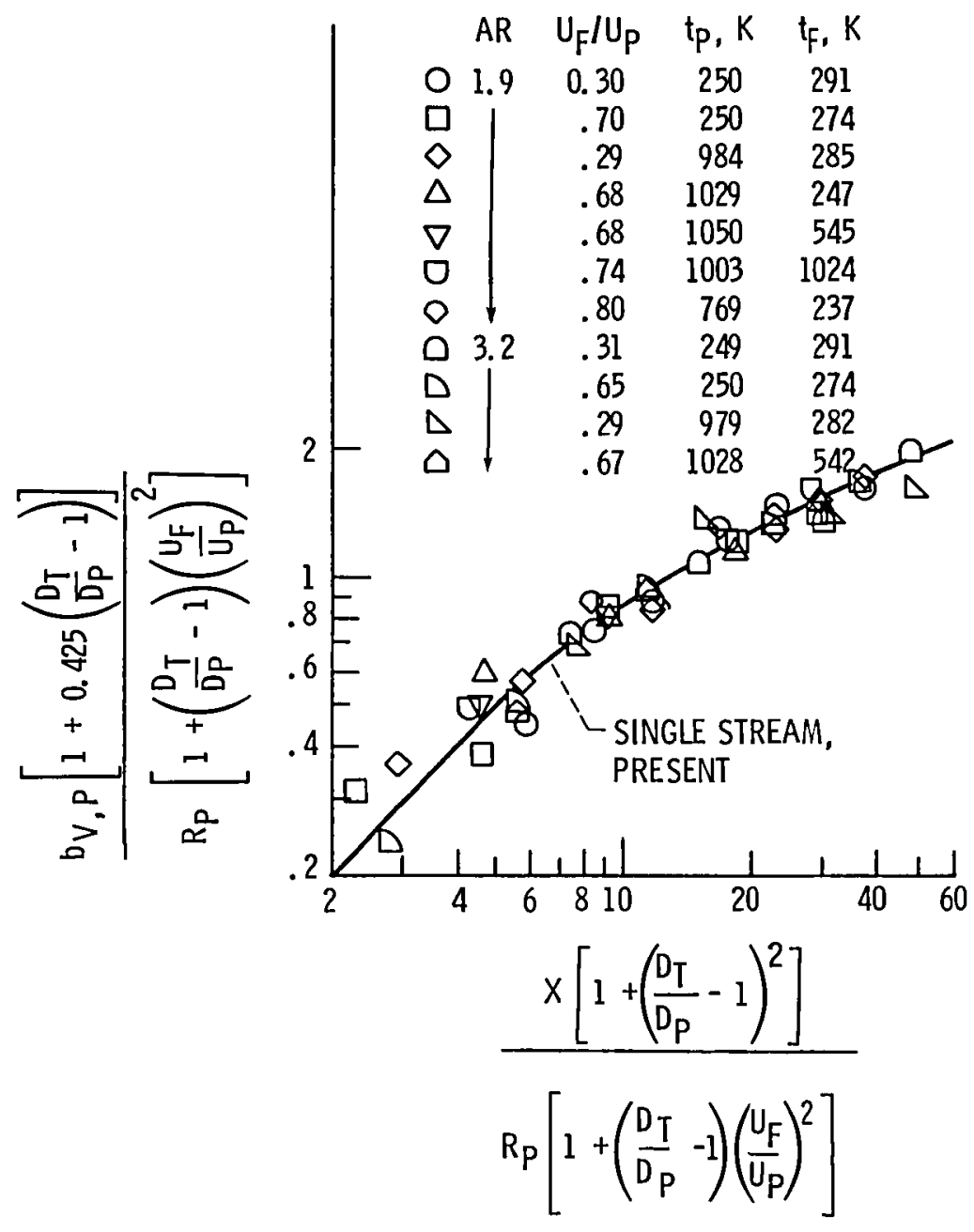

Figure 34. - Normalized two-stream primary flow velocity radial spreading.

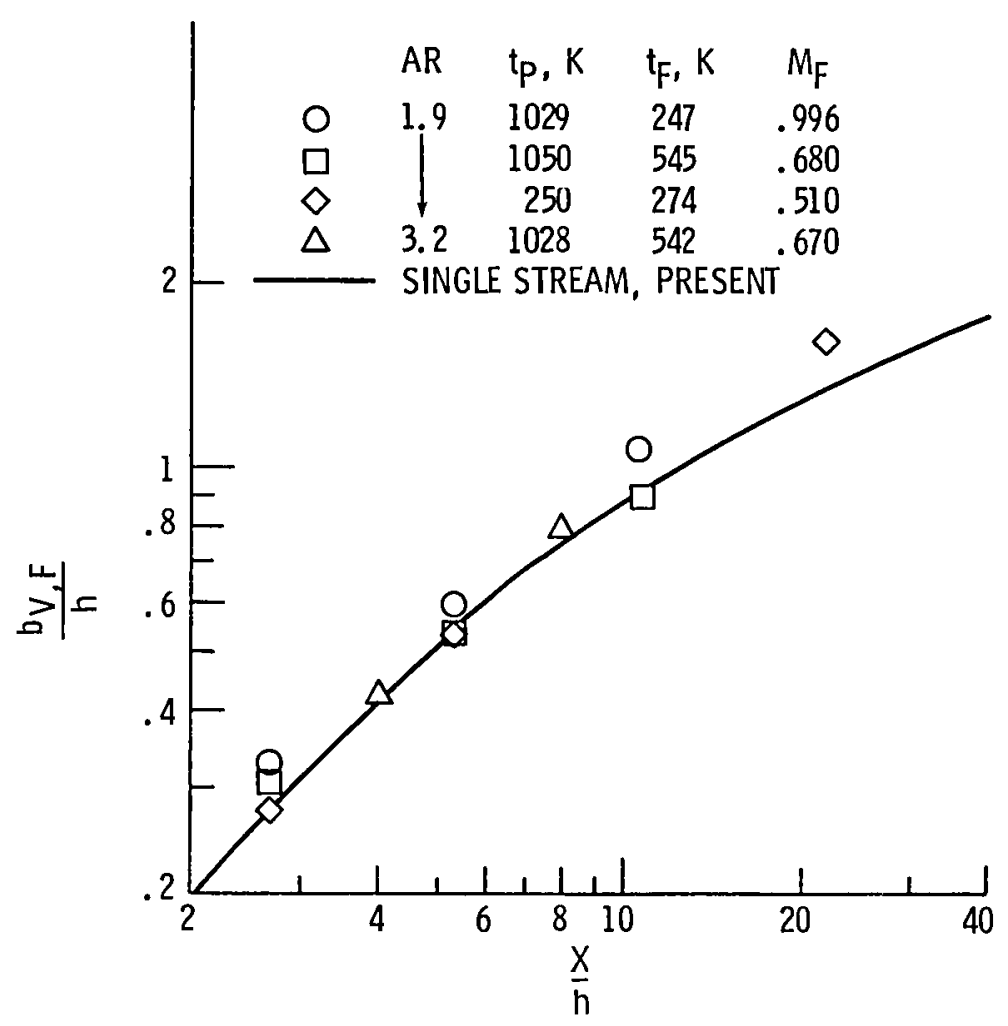

Figure 35. - Plume velocity radial spreading characteristics for fan stream. Nominal $U_{F} / U_{p}, 0.68$. 


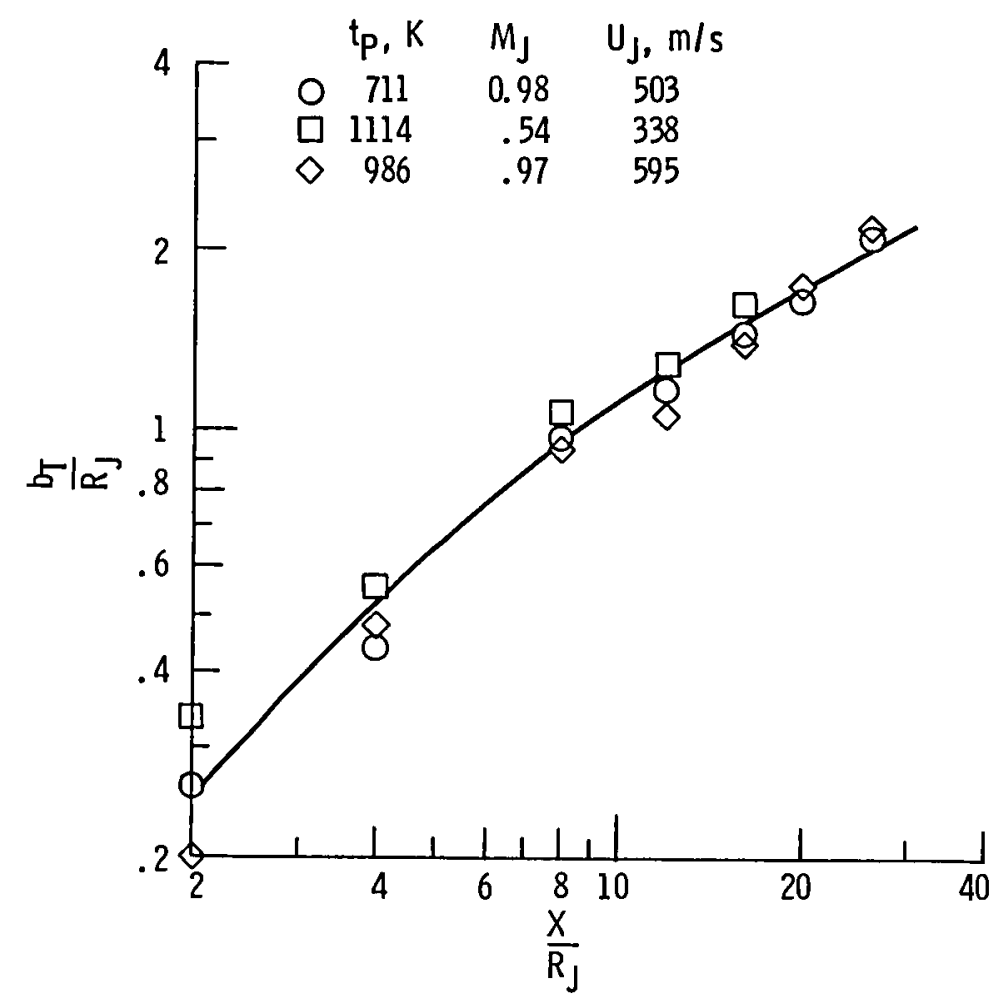

Figure 36. - Jet plume temperature radial spreading characteristics for single-stream nozzle.

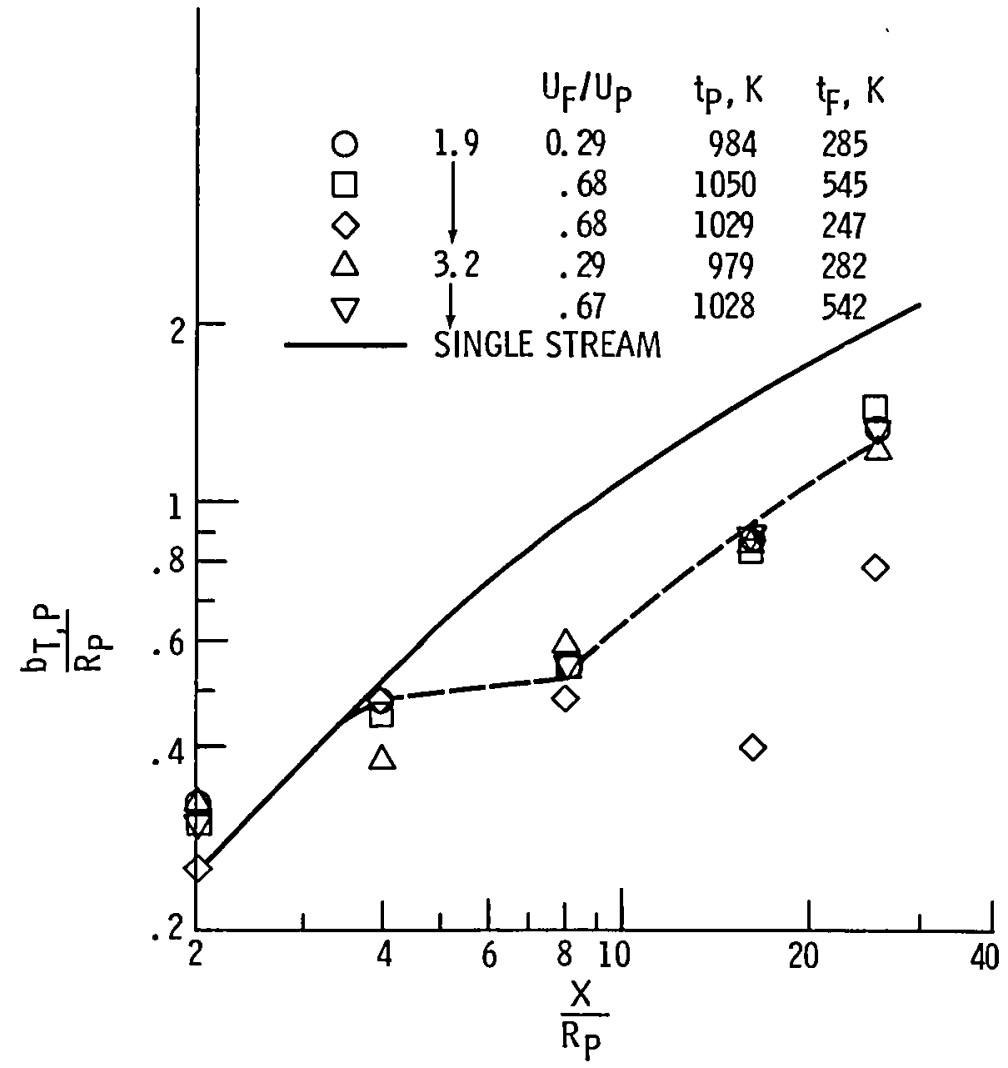

Figure 37. - Normalized two-stream primary flow temperature spreading. 


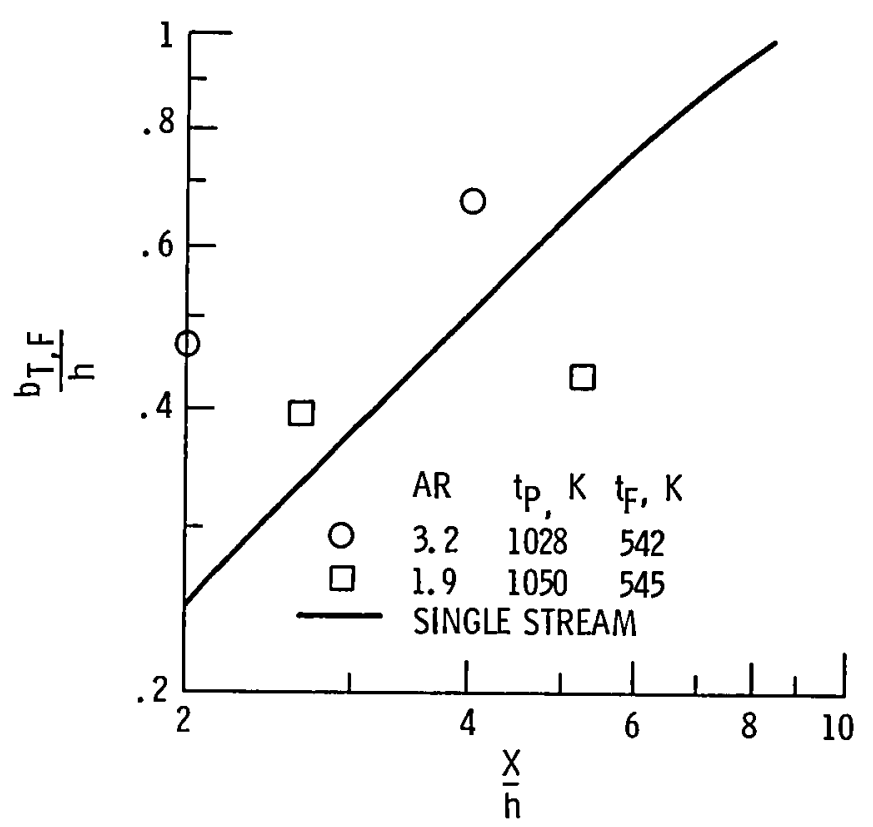

Figure 38. - Fan stream temperature spreading. Nominal $U_{F} / U_{P}, 0.68$. 



\begin{tabular}{|c|c|c|c|}
\hline $\begin{array}{l}\text { 1. Report NoNASA TM- } 83730 \\
\text { AIAA- } 84-2205\end{array}$ & \multirow{4}{*}{$\begin{array}{l}\text { 2. Government Accession No. } \\
\text { racteristics of Two- } \\
\text { Plumes }\end{array}$} & \multicolumn{2}{|c|}{ 3. Recipient's Catalog No. } \\
\hline \multirow{3}{*}{$\begin{array}{l}\text { 4. Tille and Subtitle } \\
\text { Velocity and Temperature Characteristics of Two- } \\
\text { Stream, Coplanar Jet Exhaust Plumes }\end{array}$} & & \multirow{2}{*}{\multicolumn{2}{|c|}{ 5. Report Date }} \\
\hline & & & \\
\hline & & \multicolumn{2}{|c|}{$\begin{array}{l}\text { 6. Performing Organization Code } \\
505-31-3 B\end{array}$} \\
\hline \multirow{2}{*}{\multicolumn{2}{|c|}{$\begin{array}{l}\text { 7. Author(s) } \\
\text { U. von Glahn, J. Goodykoontz, and C. Wasserbauer }\end{array}$}} & \multicolumn{2}{|c|}{$\begin{array}{l}\text { 8. Pertorming Organization Report No. } \\
\text { E-2205 }\end{array}$} \\
\hline & & \multicolumn{2}{|l|}{ 10. Work Unit No. } \\
\hline \multirow{2}{*}{\multicolumn{2}{|c|}{$\begin{array}{l}\text { 9. Partorming Organization Name and Address } \\
\text { National Aeronautics and Space Administration } \\
\text { Lewis Research Center } \\
\text { Cleveland, Ohio } 44135\end{array}$}} & \multicolumn{2}{|c|}{ 11. Contract or Grant No. } \\
\hline & & \multirow{2}{*}{\multicolumn{2}{|c|}{$\begin{array}{l}\text { 13. Type of Repont and Period Covered } \\
\text { Technical Memorandum }\end{array}$}} \\
\hline \multicolumn{2}{|c|}{$\begin{array}{l}\text { 12. Sponsoring Agency Name and Address } \\
\text { National Aeronautics and Space Administration } \\
\text { Washington, D.C. } 20546\end{array}$} & & \\
\hline \multicolumn{4}{|c|}{$\begin{array}{l}\text { 15. Supplementary Notes } \\
\text { Prepared for the Second Applied Aerodynamics Conference sponsored by the American } \\
\text { Institute of Aeronautics and Astronautics, Seattle, Washington August 21-23, } 1984\end{array}$} \\
\hline \multicolumn{4}{|c|}{$\begin{array}{l}\text { 16. Abstract } \\
\text { The subsonic jet exhaust velocity and temperature characteristics of model-scale } \\
\text { two-stream coplanar nozzles were obtained experimentally. The data obtained in- } \\
\text { cludes the effects of fan-to-primary stream velocity and temperature ratios on } \\
\text { the jet axial and radial flow characteristics. Empirical parameters were devel- } \\
\text { oped to correlate the measured data. The resultant equations are shown to be } \\
\text { extensions of a previously published single-stream jet velocity and temperature } \\
\text { correlation. }\end{array}$} \\
\hline $\begin{array}{l}\text { 17. Kay Worde (Suggested by Author(s)) } \\
\text { Jet plume } \\
\text { Jet characteristics }\end{array}$ & $\begin{array}{l}\text { 18. Distrit } \\
\text { Unc1 } \\
\text { STAR }\end{array}$ & $\begin{array}{l}\text { d - unlimited } \\
\text { ry } 07\end{array}$ & \\
\hline $\begin{array}{l}\text { 19. Socurtly Classif. (of this roport) } \\
\text { Unclass i fied }\end{array}$ & $\begin{array}{l}\text { 20. Socurtity Clessif. (of this pago) } \\
\text { Unclassi fied. }\end{array}$ & 21. No. of pages & 22. Prico" \\
\hline
\end{tabular}

"For sale by the National Technical Information Service, Springfield, Virginia 22161 
;

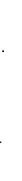


National Aeronautics and Space Administration

Washington, D.C.

20546

Otfucial Business

Penalfy for Private Une, $\mathbf{5 3 0 0}$
SNECIAL FOUATH CLASS MAIL DoOK

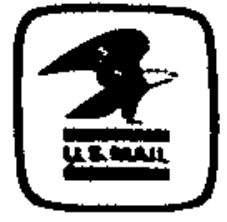

Patwo and F ces Paid Nutional Aeroneutics and. Souce Administration NASA-451 